\title{
Development of an Interdisciplinary Simulation Environment for Traffic Safety Modeling
}

A Thesis
Presented to
The faculty of the School of Engineering and Applied Science
University of Virginia
In Partial Fulfillment
Of the requirements for the Degree
Margaret McNamara of Science
Civil and Environmental Engineering

May 2014 


\section{APPROVAL SHEET}

This thesis is submitted in partial fulfillment of the

Requirements for the degree of

Masters of Science in Civil and Environmental Engineering

Margaret McNamara, Author

This thesis has been read and approved by the Examining Committee:

Dr. Brian Smith, Thesis Advisor

Dr. Brian Park

Dr. Jeff Crandall

Dr. Emily Parkany

Accepted for the School of Engineering and Applied Science:

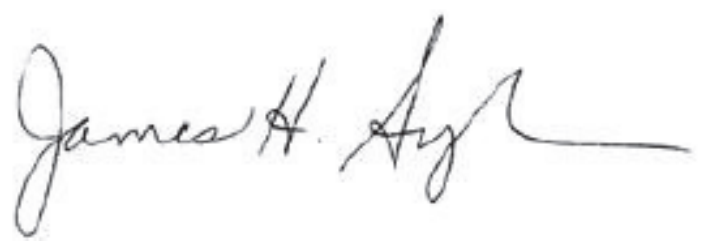

Dean, School of Engineering and Applied Science

May 2014 


\begin{abstract}
Safety research and modeling has traditionally been divided into two separate realms - that of the vehicle and that of the road. Because crashes are caused by a variety of factors - the driver, the vehicle, and the road - and their interactions, it is ideal to look at the larger picture of transportation safety. Modeling is a useful test bed for new technologies and improvements; and greater fidelity in safety modeling will allow designers to see the potential impact of an infrastructure or vehicular change before implementing it. To make the greatest impact, civil and mechanical engineers must work together to capture the entirety of the transportation system, tying together elements of traffic flow, driver behavior, and vehicle dynamics.

For this project, made possible by a University of Virginia Seed grant, an interdisciplinary model for was developed testing safety technology by linking VISSIM, a civil engineering traffic flow simulator, and MADYMO, a mechanical engineering vehicle dynamics simulator. Traffic conflicts were chosen as a surrogate for crashes due to the limitations of simulation and the rareness of crashes. The outputs of the model are the number and type of conflicts along with severity metrics and the probabilities of different injury types. Only rear-end crashes have been studied so far, but the model could be extended to cover other crash types and other explanatory variables. The model was validated on crash data from Route 50 in northern Virginia before being used for a demonstration on testing the efficacy of forward collision warning, pre-crash braking, and autonomous pre-crash braking. It is demonstrated that existing models can be tied together to examine transportation safety in terms of the roadway, vehicles, and driver and test new technologies and infrastructure improvements.
\end{abstract}




\section{Table of Contents}

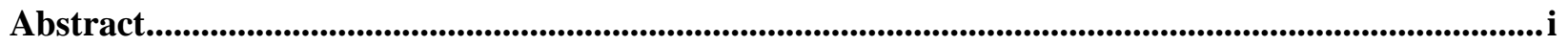

List of Tables ........................................................................................................................................................................ iv

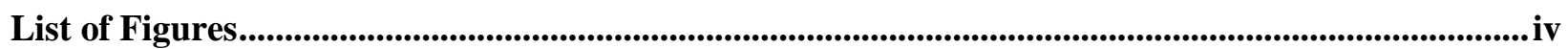

Chapter 1: Introduction ...................................................................................................................................... 1

Chapter 2: $\quad$ Literature Review ..................................................................................................................

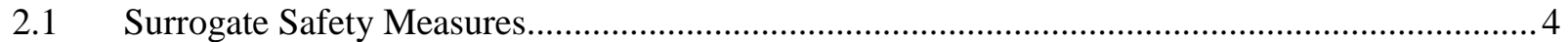

2.1.1 The Traffic Conflict Method ............................................................................................ 4

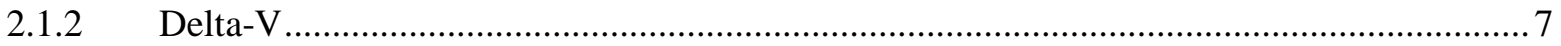

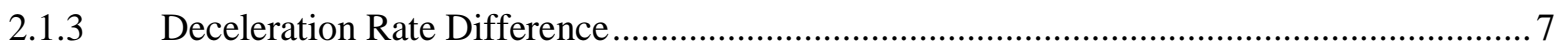

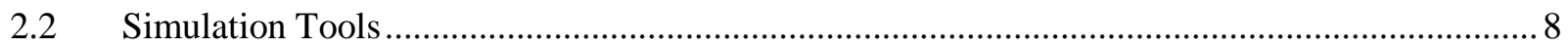

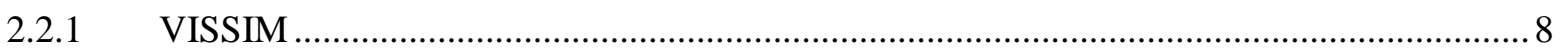

2.2.2 Surrogate Safety Assessment Model........................................................................... 9

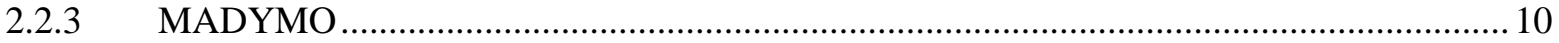

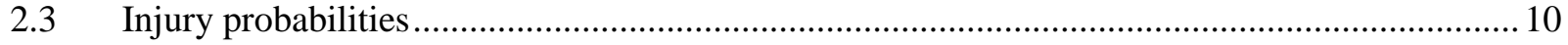

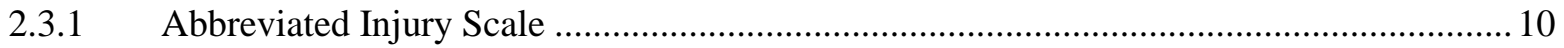

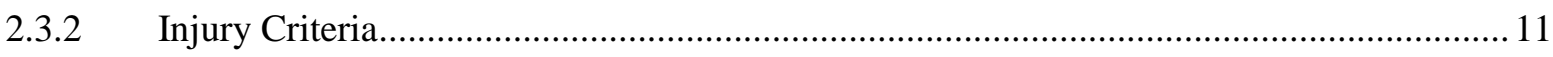

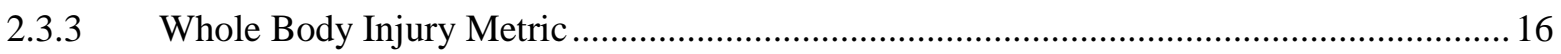

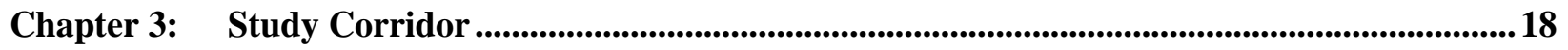

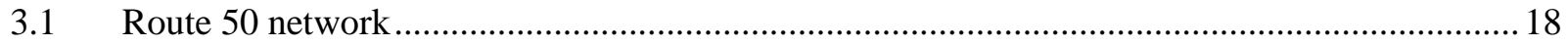

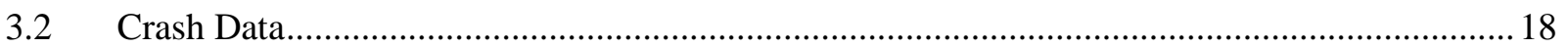

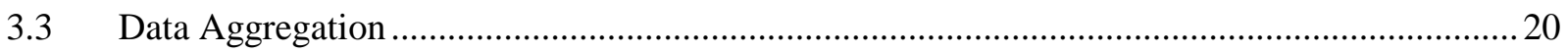

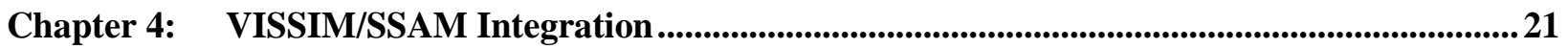

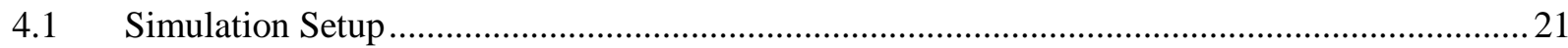

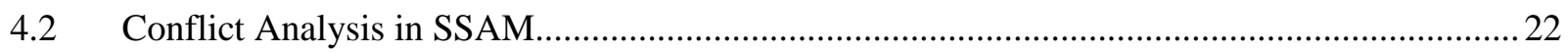

Chapter 5: MADYMO Results...............................................................................................................24

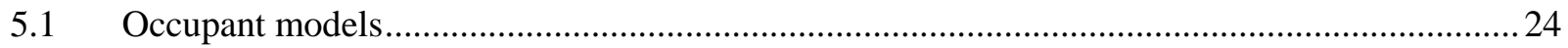

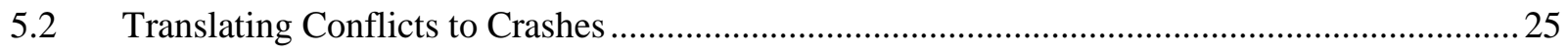

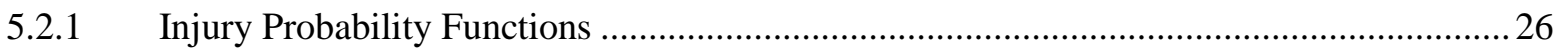

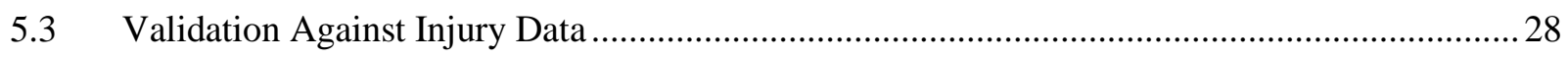

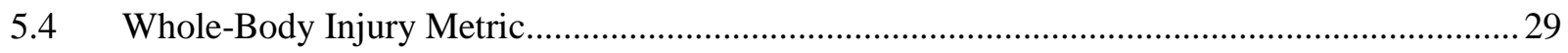




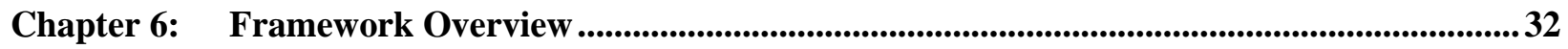

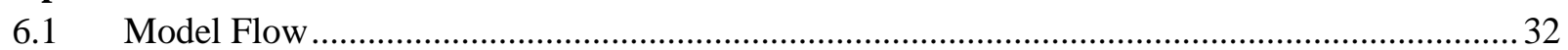

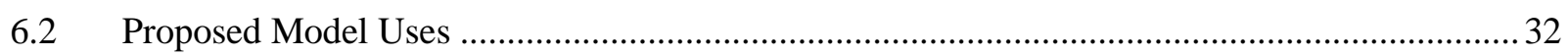

Chapter 7: Model Testing ............................................................................................................................................34

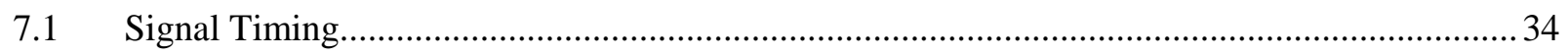

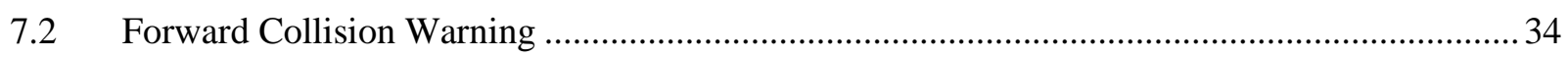

Chapter 8: Conclusions and Recommendations ...................................................................................37

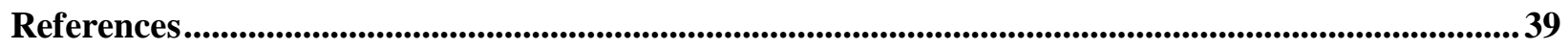

Appendix A： Logistic vs. Weibull Distributions ............................................................................................ A-1

Appendix B: Injury Function Development .............................................................................................. B-2 


\section{List of Tables}

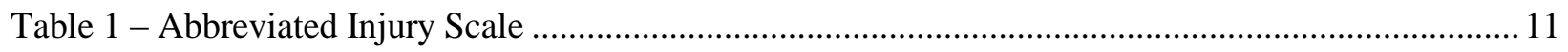

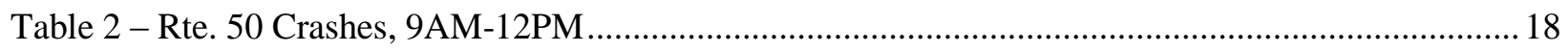

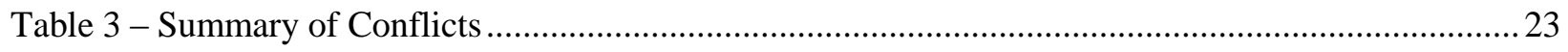

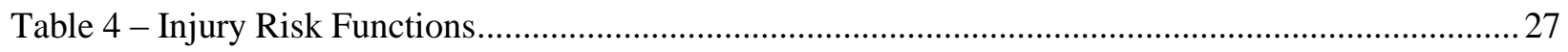

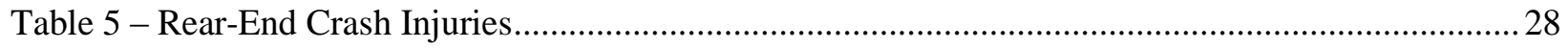

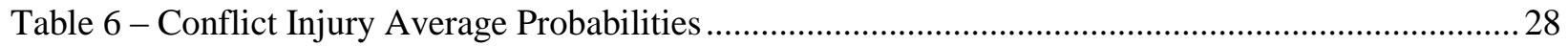

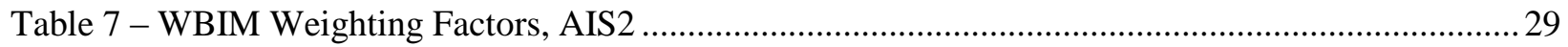

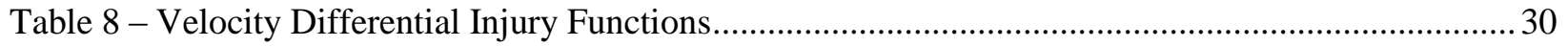

Table 9 - Summary of Results from Kusano and Gabler, 2012 ........................................................... 35

Table 10 - Conflict Injury Probabilities for Pre-Crash Systems Cases .................................................. 36

\section{List of Figures}

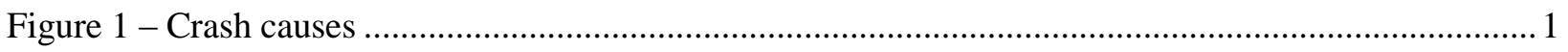

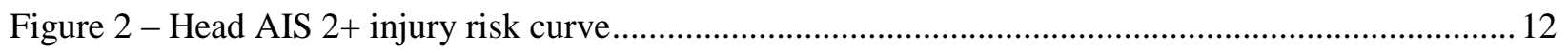

Figure 3 - Neck AIS 2+ injury probability curve …...................................................................... 13

Figure 4 - Thorax AIS 2+ injury probability curve ….......................................................................... 13

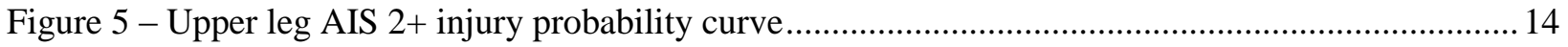

Figure 6 - Lower leg AIS 2+ injury probability curve ..................................................................... 15

Figure 7 - Ankle and foot AIS 2+ injury risk curve …...................................................................... 15

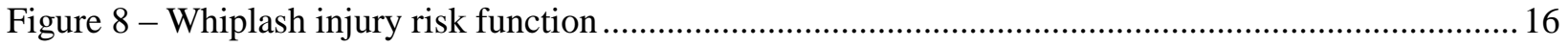

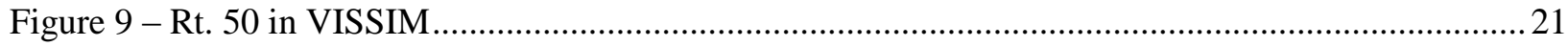

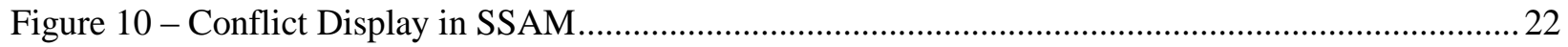

Figure 11 - Occupant Models: a) Hybrid III b) BioRID II ...................................................................24

Figure 12 - Hybrid III occupant model with airbag deployed................................................................25

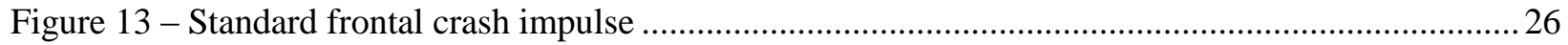

Figure 14 - Logistic vs. Weibull Distributions for a) neck injuries and b) chest injuries ........................27

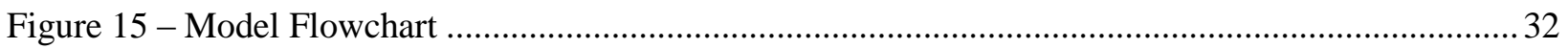




\section{CHAPTER 1: INTRODUCTION}

The recent trend in transportation safety is towards a safe systems approach, which aims to minimize fatalities and serious injuries related to road crashes. Many of these systems, such as Sweden's Vision Zero, have a goal of zero road fatalities, which is based in the philosophy that no loss of life is acceptable (Vision Zero Initiative, 2013). Research on this front has failed to cross traditional disciplinary boundaries, however. Mechanical engineers are focused on the vehicle while civil engineers deal with the infrastructure. The objective of this research was to bridge that gap, creating an interdisciplinary modeling environment that can be used to test the safety efficacy and interrelationship of new technologies and infrastructure improvements.

Crashes are caused by a variety of different factors that can be broken into factors relating to the driver, the vehicle, and the roadway. One study of crashes in the United States and Great Britain found that there are significant interaction effects between these major factors, summarized in the Venn diagram in Figure 1 (Rumar, 1985). In particular, the interaction effects between the driver and the roadway are significant (27\%) and are not generally accounted for in either road or vehicle modeling. In addition, 3\% of crashes are caused by a combination of driver, roadway, and vehicle crashes, which is a difficult area to study through current methods.

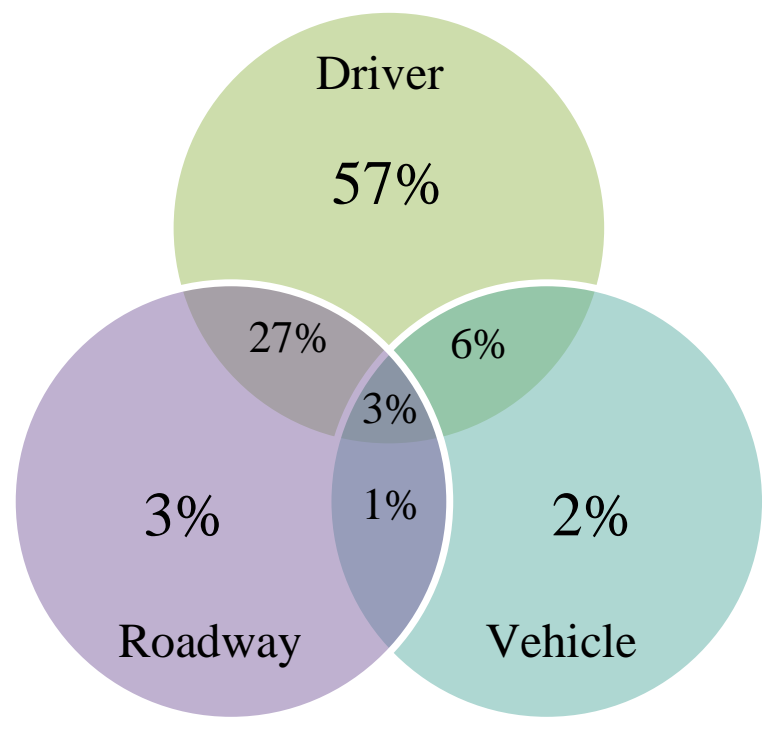

Figure 1 - Crash causes. Reproduced from Rumar (1985).

In a review of the current state of the practice on simulation in traffic safety, Young, Sobhani, and Sarvi (2014) found that there have been many successful applications of conflict analysis to study crashes from 
the traffic flow perspective. There have also been a number of statistical and numerical models that can accurately predict crashes, but do not tie into the road conditions, traffic flow, etc. Existing statistical models cover factors affecting the number and severity of crashes, but driving behavior is rarely accounted for. The authors concluded that, while much progress has been made on this front, "clearly an important area of research is the total traffic system or network" (Young, Sobhani, \& Sarvi, 2014).

This research was made possible through a research seed grant from the University of Virginia engineering school in order to promote collaboration between two existing research centers, the Center for Applied Biomechanics and the Center for Transportation Studies. Each center brought its own expertise to the project, ranging from traffic flow simulation to vehicle dynamics. The key pieces of software identified early in the project were VISSIM, a microscopic traffic flow simulator by PTV Group and MADYMO, a vehicle dynamics simulator by the Netherlands Organization for Applied Scientific Research (TNO).

VISSIM's main use is to simulate traffic flow for operations and planning purposes and the car-following logic used to control driver behavior does not permit crashes. Crashes are very difficult to model accurately because most result at least in part from driver error, which is prohibitively difficult to model. Instead, traffic conflicts were chosen as a surrogate for crashes. These near-crash situations can be extracted from special trajectory files output by VISSIM using the FHWA's Surrogate Safety Assessment Model (SSAM). After these conflicts are extracted and analyzed in SSAM, conflict parameters are used to model the theoretical crash in MADYMO.

MADYMO is able to measure the forces on the occupant in both the striking and struck vehicles. Injury risk functions are used to translate these forces to a likelihood of injury to the relevant areas of the body, separated by tiers of the Abbreviated Injury Scale (AIS). To more succinctly capture the safety of a crash occupant, these injury probabilities are combined by a weighted function called the Whole Body Injury Metric (WBIM). This function uses medical and quality of life costs to prevent even comparisons between injuries that affect the victim very differently. 


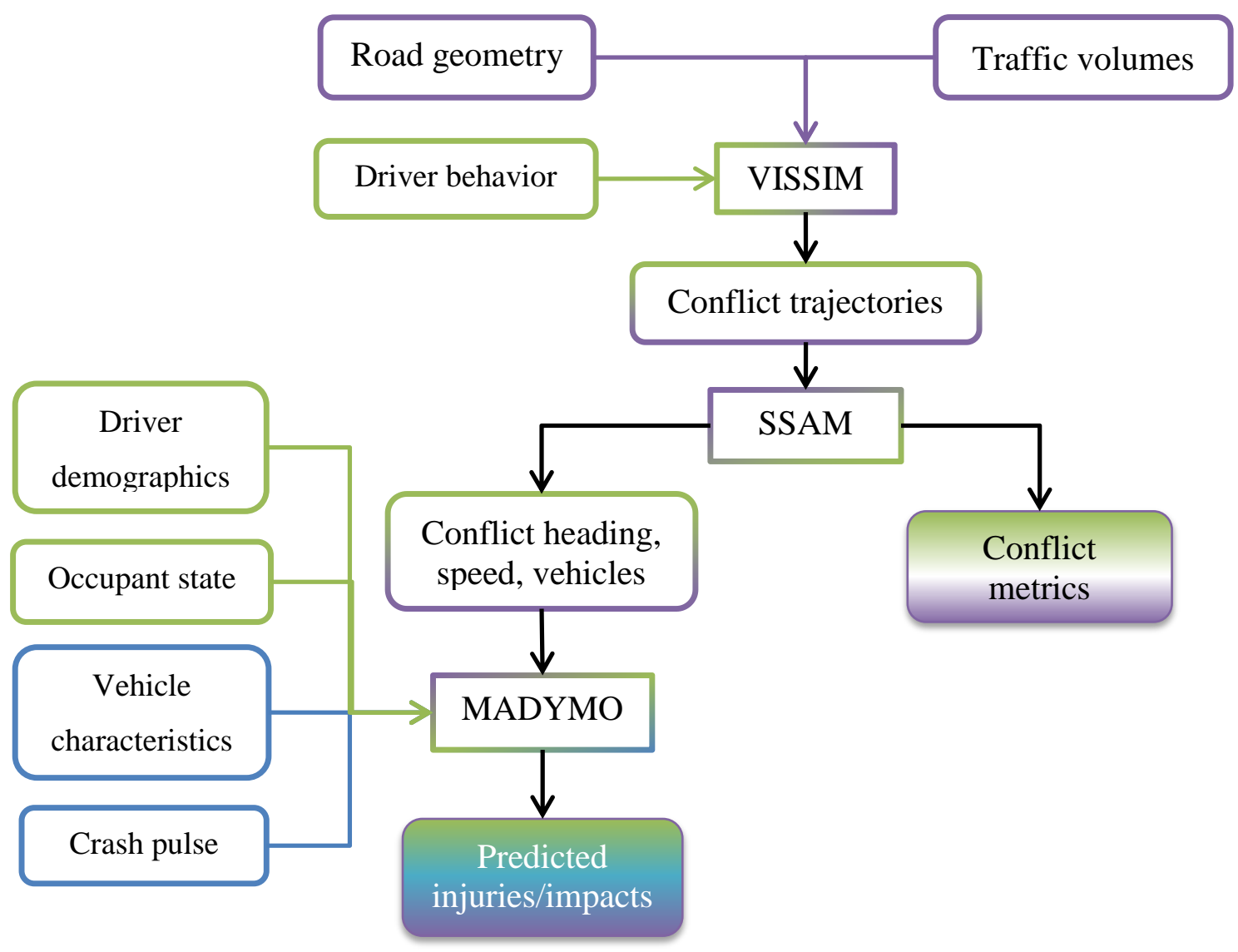

Figure 2 - Model Flowchart

Figure 2 above lays out the proposed model flow, using the same color scheme as the Venn diagram in Figure 1 to denote driver (green), vehicle (blue), and roadway (purple) characteristics. This framework will be discussed in more detail in Chapter 6, after each of the component parts is reviewed.

Chapter 2 contains a literature review covering the traffic conflict method, surrogate measures chosen, and the three programs used. Chapter 3 details the study corridor and real-world crash data used for validation. The traffic flow and conflicts simulation in VISSIM and SSAM is covered in Chapter 4 and Chapter 5 reviews the traffic dynamics simulation done in MADYMO. Chapter 6 gives an overview of the final model framework and Chapter 7 details two tests carried out to demonstrate its capabilities. The thesis concludes with conclusions and recommendations for further research in Chapter 8. 


\section{CHAPTER 2: LITERATURE REVIEW}

The literature review focused on surrogate safety measures, the chosen simulation tools, and the functions used to derive injury probabilities from simulated forces.

\subsection{SURROGATE SAFETY MEASURES}

Surrogate safety measures are metrics intended to replace or supplement crash data in safety assessments. They aim to overcome the largest drawbacks of crash data, particularly the issue of small sample sizes. The traffic conflict method is the most popular method.

\subsubsection{ThE TRAFFIC CONFLICT METHOD}

The most commonly used surrogate safety measure is traffic conflicts, that is, traffic interactions that might have led to a crash if not for evasive action taken by the drivers. At first, conflicts were measured by observers by noting evasive actions such as brake lights or swerving. Amundsen and Hyden formally defined a traffic conflict as "an observable situation in which two or more road users approach each other in space and time for such an extent that there is a risk of collision if their movements remain unchanged" (1977).

Traffic conflicts are a useful surrogate measure because they occur much more frequently than crashes and typically arise from similar safety-critical situations. By the definition above, every crash is preceded by a conflict, which strengthens the link between the two measures. This allows conflicts to be used as a surrogate for crash frequency in safety studies such as before and after comparisons.

Conflicts can be characterized by a number of metrics, such as time to collision (TTC), which is the time at any point during a conflict that it would take the two vehicles to collide if neither takes action.

Frequently the minimum TTC experienced during a conflict is used to describe its severity. A similar metric is the post-encroachment time (PET), or the time from when the encroaching vehicle leaves the second vehicle's path to the time the second vehicle reaches the conflict point. Other metrics include the maximum deceleration during the conflict, the difference in the speed of the vehicles, and the maximum speed.

\subsubsection{CONCERNS WITH THE TRAFFIC CONFLICT METHOD}

The traffic conflict method was first formally defined by Perkins and Harris in 1967 as observation and counting of evasive actions taken by cars (Chin \& Quek, 1997). As it gained traction, certain weaknesses 
and concerns surfaced, such as inconsistency of definition and application, validation concerns, and linking conflicts and crashes. Many of them have been addressed in subsequent research and development of the method.

Until Amundsen and Hyden's definition at the first conference on traffic conflicts, there was no agreedupon quantitative definition of conflicts. Evasive actions are usually marked by brake lights or sudden swerving or lane changing, though not every instance of these is necessarily evasive. In observation studies, this distinction is highly subjective and requires training to be applied consistently. It is also important that the definition of conflicts be connected to the occurrence of crashes, and this definition excludes crashes in which neither driver takes evasive action.

Using the time and space proximity definition still allows some room for interpretation. Measures such as TTC have further formalized the method, but researchers must remain clear and internally consistent in their definitions of conflicts, particularly in the delineation of severity levels. The data for these qualitative measures can be difficult to obtain outside of simulation, however. While severe conflicts are easier to observe, discarding less critical encounters discards a large portion of the available data (Chin \& Quek, 1997).

Validation of traffic conflict data has proved an obstacle for the establishment of the method. Some researchers have had success while others have failed to validate their data (El-Basyouny \& Sayed, 2013). Part of this problem is due to the statistical variation and inaccurate reporting of crashes themselves (Chin \& Quek, 1997).

Further research has failed to develop a consistent proportional relationship between crashes and conflicts, though they are related in describing safety-critical situations. Proportions have been established for individual sites, but differing characteristics hamper generalization. This does not invalidate the method, however, as conflicts can still be reliably compared to other conflicts.

\subsubsection{COLLECTING CONFLICT DATA}

Conflict data are generally collected by observation, video analysis, or simulation. The quality of the data can vary wildly depending on the method chosen. A conflict observation or video analysis study requires trained observers to visit a site or watch recorded traffic and note each conflict event. This method is subject to a lot of personal error and subjective variance, including inconsistency in recording. Using video recordings can facilitate repeated viewing, but the results are lower quality than on-site observation (Chin \& Quek, 1997). Training observers is also expensive and time consuming. 
Video from sites can also be analyzed by computer, bypassing the need for a trained observer, and is faster but less accurate. Identifying conflicts at intersections is particularly difficult due to the complexity of the movements and partial occlusion by other vehicles, though research has been expanding the capability of automated video analysis (Saunier \& Sayed, 2006) (Saunier \& Sayed, 2007).

Simulation of conflicts using microscopic traffic simulators such as VISSIM and PARAMICS is attractive for predicting safety at a site, particularly when studying proposed infrastructure or operational changes. However, limitations of the simulator's driving algorithms can impede the analysis. Simulation allows for a lot of data to be developed without the costs associated with observation or video analysis. These data can be useful to study theoretical situations, making it attractive to researchers. Simulation is discussed further in Sections 2.2.1 and 2.2.2 .

\subsubsection{A CAUSAL MODEL OF TRAFFIC CONFLICTS}

A causal model relates a set of external variables to a set of internal variables that each respond to the external variables through a structural equation. Davis et al. (2011) propose a causal model of traffic conflicts to gain a better understanding of the relationship between conflicts and crashes. In this model, $\mathrm{U}$ denotes the set of possible initiating conditions, $\mathrm{X}$ the set of evasive actions, and $\mathrm{Y}$ the set of possible crash outcomes, ranging from conflicts to collisions. In set $Y$ is a critical value $y_{c}$ such that if $y(u, x)<y_{c}$, a crash occurs.

Crashes are "a collection of events where all alternatives to handle the situation safely have vanished one by one" (Svensson and Hyden, 2006). Hence, the initiating condition and possible evasive actions must be taken into account. The values of the model are defined such that $\mathrm{U}_{1}$ denotes all initiating conditions where a crash never occurs and $x_{\min }(\mathrm{u})=\mathrm{x}_{\mathrm{i}}$ gives the minimum evasive action to avoid a crash in $\mathrm{U}_{\mathrm{i}}$. In this way, the model incorporates the importance of the initial conditions and the choice of evasive action to the occurrence of a conflict or crash.

Further framework of the model provides for the probability of a crash based on ( $\mathrm{u}, \mathrm{x})$, formalizing the counterfactual relationship of conflicts to crashes, and places a lower bound on crash probability based on limited knowledge of the evasive actions. This model can be used to extend observations of non-crash interactions to glean information about crashes. However, it is merely a theoretical outline and must be extended in order to be practically applied. The greater understanding of the importance of evasive actions to the crash-conflict ratio is a useful contribution. 


\subsubsection{DELTA-V}

Delta-V $(\Delta \mathrm{V})$ is the change between the pre- and post-crash velocities of each vehicle. It has been used as a metric for crash severities since the 1970s, but has only recently been applied to conflicts. As explained by Carlson, delta- $\mathrm{V}$ "is related to the decelerations and therefore the forces imposed on occupants" (1978). Groups like the International Institute for Highway Safety (IIHS) use delta-V to quantify crash severity, and it is the primary metric used for severity in the National Automotive Sampling System (NASS) (Arbelaez, Baker, \& Nolan, 2005).

Shelby (2011) proposed an application of delta-V to conflicts as a way of measuring their severity. Conflict severity is broken down into three parts which endeavor to clarify the various meanings behind the term. Collision propensity is the probability that a conflict results in a collision and collision severity is the expected magnitude of that potential collision. Conflict severity is redefined as the expected severity of the conflict scenario, considering the distribution of crash and no crash scenarios as well as the potential collision severity. The crash propensity can be determined using a distribution of perceptionreaction times and potential collision severity is described with delta-V.

Compared with other metrics of conflict severity, delta-V leads to a more accurate prediction due to its inclusion of direction as well as force. For example, Shelby compares two collisions, one head-on and the other rear-end, where the maximum speed of a vehicle during the conflict, another common severity metric, is the same. The delta- $\mathrm{V}$, however, correctly identifies the head-on collision as being more severe (assuming a perfectly inelastic collision for simplicity) because it also contains information about the direction. Similarly, delta-V was able to discriminate between three situations with identical TTC to gain more information about their collision severities.

Shelby suggests that to calculate collision propensity, the point where a traffic conflict emerged must be determined, which corresponded to a TTC of $2.8 \mathrm{~s}$ for the given scenarios. This is much greater than the frequently-cited TTC threshold of $1.5 \mathrm{~s}$ (Gettman, 2008). However, a higher threshold will give more false positives, so instead a perception-reaction time distribution can be used to calculate collision propensity.

\subsubsection{DECELERATION RATE DIFFERENCE}

The deceleration rate difference (DRD) is the difference in acceleration or deceleration of the two vehicles before a crash. Park et al. studied crash and near-crash trajectories for rear-end crashes on a crash-prone part of I-94 in Minnesota (2011). TTC was selected for analysis due to its relation to driver 
application of brakes. To gain a more intuitive proportional relationship with crash risk, this value was expressed instead as inverse TTC (iTTC). TTC decreases with proximity to a crash, so iTTC increases with increasing crash risk. Based on a sensitivity analysis, an iTTC of $0.4 \mathrm{~s}^{-1}$ was chosen to balance capturing all crashes with providing enough time for adequate braking. This corresponds to a TTC of 2.5 $\mathrm{s}$, which is the standard assumed value for driver perception-reaction time for unexpected events.

To supplement the iTTC threshold due to its $75 \%$ false positive rate, the deceleration rate difference was considered. The non-crash vehicles largely applied the brakes "quickly and dramatically" when the iTTC reached near 0.4 (Park, Chen, \& Hourdos, 2011). On the contrary, crash vehicles did not brake at this point and were not able to stop in time. For each of the 20 dangerous cases selected by iTTC of 0.4 (15 false alarms and 5 crashes), the DRD was computed, and $15 \mathrm{ft} / \mathrm{s}^{2}\left(4.5 \mathrm{~m} / \mathrm{s}^{2}\right)$ was found to be the threshold between the two cases. So in conjunction, these two thresholds combined were able to detect all five of the crashes without any false positives.

This value has not been independently reviewed or validated, however. There are concerns with the small sample size that this value was gleaned from, but it is beyond the scope of this research to validate it. DRD is an intuitive method for filtering crashes, but it is recommended that more research be done on the subject.

\subsection{SIMULATION TOOLS}

Three simulation tools were chosen for use in this project: VISSIM, a traffic flow simulator, the Surrogate Safety Assessment Model (SSAM) for extracting and analyzing traffic conflicts, and MADYMO, a vehicle dynamics simulator.

\subsubsection{VISSIM}

PTV VISSIM is a microscopic traffic simulator that is based in driver-vehicle units and was developed by the PTV Group. Each driver-vehicle unit has characteristics stochastically derived from population distributions, such as desired speed, following distance, destination, and route choice. The vehicle following behavior is governed by the psycho-physical car-following model developed by Wiedemann in 1994 (VISSIM 5.40 - User Manual, 2012).

The Wiedemann car-following model dictates how a driver slows when approaching a slower moving driver based on his perception threshold. His speed oscillates as he continues to follow this driver due to human inability to accurately perceive relative speed. Stochastic distributions of parameters such as 
desired speed and safe following distance are used to mimic individual driver characteristics. Drivers also have parameters for comfortable and emergency deceleration, and the program will go to great lengths to avoid simulating crashes.

Because simulated drivers do not engage in illegal or sudden behavior, the fidelity to actual safety-related situations is questionable. However, behavior-based modeling is difficult to develop and computationally intensive to perform. Conflict research is currently the simplest way to apply microscopic simulation to safety research.

\subsubsection{SuRrogate SAFETY ASSESSMENT MOdEL}

The Surrogate Safety Assessment Model (SSAM) was developed by Siemens on a Federal Highway Administration (FHWA) contract for conflict analysis. It analyzes trajectory files which can be output from a number of traffic simulators, including VISSIM. Conflicts are identified and filtered by TTC and PET by either user-defined or default values. Each conflict is presented to the user along with a number of measures and identifying information.

Conflicts are categorized as rear-end, lane-change, or crossing conflicts based on link and connector data from the simulator or, failing that, the conflict angle (where $180^{\circ}$ is the heading of the first vehicle and $0^{\circ}$ is directly behind it), which can be seen in Figure 3. Namely, a rear-end conflict is either one where both vehicles remain in the same lane or if the conflict angle is between $-30^{\circ}$ and $+30^{\circ}$. A crossing conflict is defined where the conflict angle is between $-85^{\circ}$ and $+85^{\circ}$ and either vehicle changed links. A lane change conflict occurs when either vehicle changes lanes or the conflict angle is between $\pm 30^{\circ}$ and $\pm 85^{\circ}$.

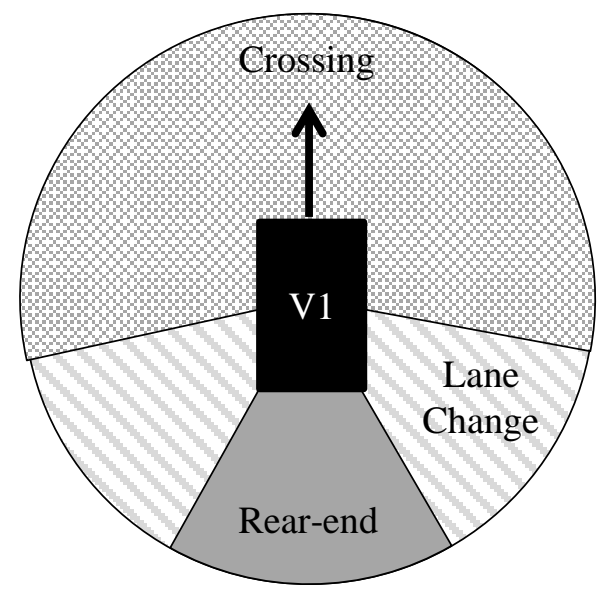

Figure 3 - Conflict Angles in SSAM

In the SSAM Final Report, Gettman et al. used 83 intersections to validate SSAM's conflict-predicting ability (2008). The simulated conflicts were compared with crash data collected by insurance companies 
and used to rank the intersections with a variety of metrics. There was a statistically significant correlation between the simulated and field-collected data, however the $\mathrm{R}^{2}$ value for total conflicts and total crashes was only 0.41 . This is outperformed by traditional assessment based on average daily traffic, with an $\mathrm{R}^{2}$ of 0.68 . Conflicts and crashes are both correlated with increased volume, a measure of exposure, so they will naturally be correlated with one another to some degree. Conflict analysis from VISSIM is sensitive to a number of parameters, including the placement of priority rules, which govern driver behavior at permissive left turns and unsignalized intersections for things like gap acceptance.

Ultimately, SSAM was chosen for use due to the lack of an alternate method for simulating crashes in normal traffic conditions. In this modeling effort, conflicts will only be compared with other conflicts to determine changes in safety, eliminating the need for a consistent mapping function between crashes and conflicts.

In order to take advantage of the findings of Park et al. on deceleration rate difference, the source code of SSAM was rewritten so that it also calculates the DRD from each conflict's trajectory (So, Park, Wolfe, $\&$ Dedes, 2014). Data can then be exported as a csv file for filtering and further analysis.

\subsubsection{MADYMO}

MADYMO (Mathematical Dynamic Models) was developed by the Netherlands Organization for Applied Science Research (TNO) Automotive Safety Solutions division (TASS) to analyze occupant safety systems in automobiles and other transit vehicles. It performs multi-body simulation of occupants subjected to a crash pulse.

For frontal applications, the model consists of a steering column, seat, three-point belt system, an airbag and the Hybrid III $50^{\text {th }}$ percentile male dummy. The vehicle components are modeled as a system of rigid bodies and joints, where the joint types determine the deformation types that the model can undergo. The program performs multi-body and finite-element analysis to determine the deformations during the crash and the subsequent forces on the dummy occupant.

\subsection{INJURY PROBABILITIES}

\subsubsection{ABBREVIATED INJURY SCALE}

The Abbreviated Injury Scale is a severity scoring system developed by the Association for the Advancement of Automotive Medicine that classifies each injury by body region from a score of 1 (minor) to 6 (maximal). Each injury sustained by an occupant is given an AIS code, and the victim is 
sometimes classified by the maximum AIS injury sustained, or the MAIS. A full AIS code contains information about the body region, type of anatomical structure injured, the level (fracture, rupture, laceration, etc.), and the severity (AAAM, 2014).

This report focuses on the severity of the injury, scored from 1 for minor injuries with no chance of death to 6, which are maximal injuries that are currently untreatable. The coding for injuries is detailed in Table 1 below (AAAM, 2014).

Table 1 - Abbreviated Injury Scale

\begin{tabular}{|l|l|l|l|}
\hline AIS Code & Injury & Example & $\%$ probability of death \\
\hline 1 & Minor & Superficial laceration & 0 \\
\hline 2 & Moderate & Fractured sternum & $1-2$ \\
\hline 3 & Serious & Open fracture of humerus & $8-10$ \\
\hline 4 & Severe & Perforated trachea & $5-50$ \\
\hline 5 & Critical & Ruptured liver with tissue loss & $5-50$ \\
\hline 6 & Maximum & Total severance of aorta & 100 \\
\hline
\end{tabular}

\subsubsection{INJURY CRITERIA}

Injury criteria are the mappings from engineering measurements obtained in tests using crash test dummies or computer models to probability of humans sustaining certain types and severities of injury (Eppinger, et al., 1999). To develop logistic regression models for the head, neck, and thorax, the level of severity of each injury in the tests was coded using the AIS manual, and injuries of AIS $\geq 3$ were coded as "injury" while no apparent injury and those with AIS $<3$ were coded "no injury." The regression was performed with the null hypothesis that the dependent variable (injury or no injury) and candidate independent variables, such as spine acceleration or axial force on the neck. Model goodness of fit was measured with the $-2 \log$ likelihood ratio, which measures the probability that the independent variable explains the outcomes.

\subsubsection{HEAD}

For head injuries in front impact crashes, the head injury criterion (HIC) was developed that incorporates the magnitude of head acceleration as well as information on the duration. NHTSA developed a standard equation for HIC, Equation 1, below, based on previous research, where $t_{1}$ and $t_{2}$ are two arbitrary times 
(in seconds) during the duration of the crash. Acceleration is measured in multiples of the gravitational constant. NHTSA defines $\left(t_{2}-t_{1}\right) \leq 15$ ms (Eppinger, et. al., 1999).

$$
H I C=\max \left[\frac{1}{t_{2}-t_{1}} \int_{t_{1}}^{t_{2}} a(t) d t\right]^{2.5}\left(t_{2}-t_{1}\right)
$$

Injury risk curves were developed by Prasad \& Mertz based on a range of experimental tests and then expanded by NHTSA to include all AIS levels (Adam, 2011). For AIS 2, the expression is given below (NHTSA, 1997) and is graphed in Figure 4.

$$
p(\text { AIS } 2)_{\text {head }}=\frac{1}{1+e^{2.49+200 / H I C}-0.00483 H I C}
$$

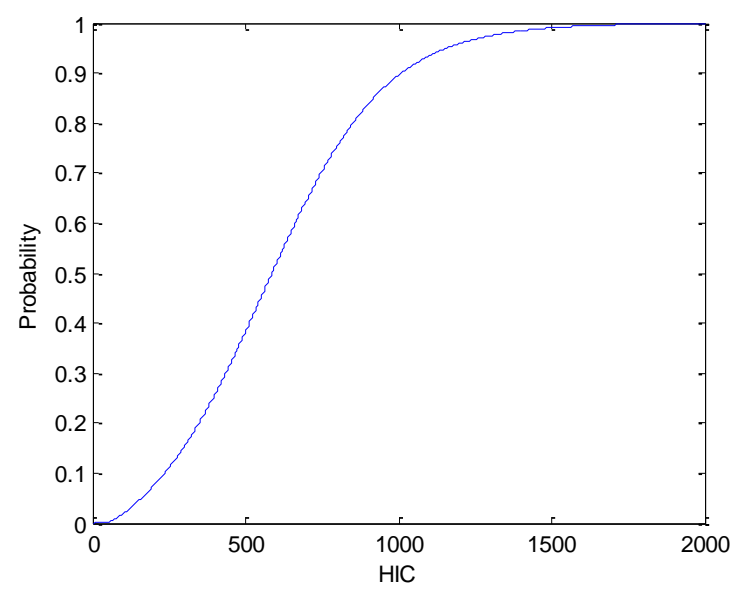

Figure 4 - Head AIS 2+ injury probability curve

\subsubsection{NECK}

For neck injuries, the axial load on the spine $\left(\mathrm{F}_{\mathrm{Z}}\right)$ and the flexion/extension bending moment at the occipital condyles, which comprise part of the joint between the skull and the neck, $\left(\mathrm{M}_{\mathrm{Y}}\right)$ are measured. The normalized neck injury criterion $\mathrm{N}_{\mathrm{ij}}$ defines the maximum acceptable load of each type in both directions, i.e., tension/compression and flexion/extension, shown in Equation 3. The values are normalized to the critical intercept of the tolerance line on each axis to control for unique dummy parameters.

$$
N_{i j}=\frac{F_{Z}}{F_{\text {int }}}+\frac{M_{y}}{M_{\text {int }}}
$$

The logistic regression performecd by Eppinger, et. al. (1999) can be seen below in Equation 4 for AIS 2+. The graph is shown in Figure 5. 


$$
p(A I S \geq 2)_{h e a d}=\frac{1}{1+e^{2.054-1.195 N_{i j}}}
$$

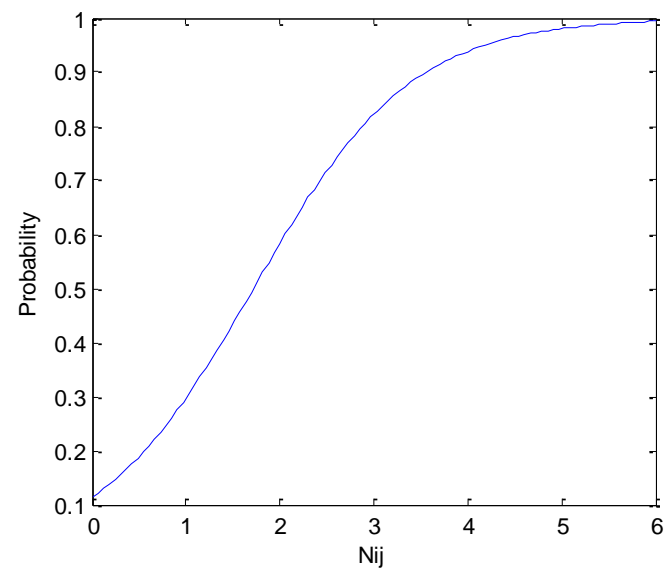

Figure 5 - Neck AIS 2+ injury probability curve

\subsubsection{CHEST}

Thoracic injuries are measured by chest displacement, which are measured at five points - upper center, upper right, upper left, lower right, and lower left. Of these five, the maximum deflection $\left(D_{\max }\right)$ is taken as the injury criterion. This value was determined through testing the fit of logistic regression models based off of a number of metrics, including spinal acceleration and central chest displacement.

$$
p(A I S \geq 2)_{\text {chest }}=\frac{1}{1+e^{1.8706-0.04439 D_{\max }}}
$$

Equation 5 above is the injury probability for AIS $2+$ thoracic injuries. The probability curve is shown below in Figure 6, with $\mathrm{D}_{\max }$ measured in $\mathrm{mm}$.

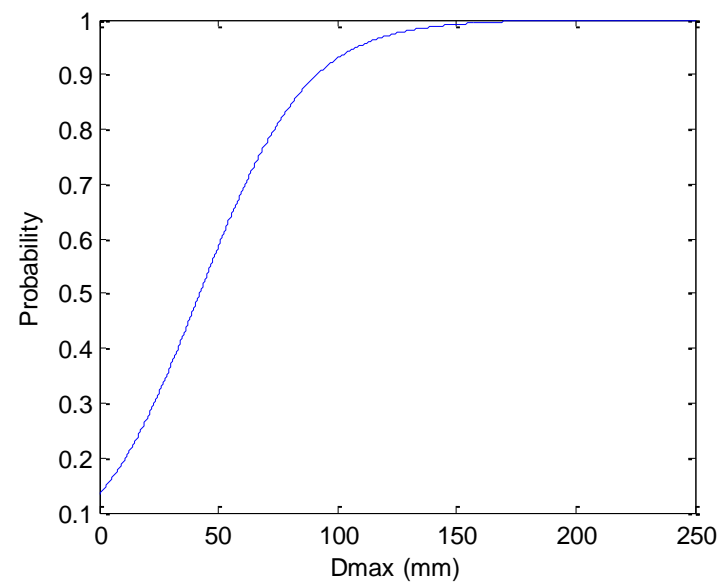

Figure 6 - Thorax AIS 2+ injury probability curve 


\subsubsection{LOWER LIMB}

Lower limb injuries are divided into two categories: thigh and leg. Thigh injuries are measured by the axial force on the femur. Leg injuries are commonly measured by axial force on the tibia, though a combined tibia index (TI) has also been developed that takes into account the bending moment. The critical axial compressive force and bending moment for each dummy are used to normalize the force. However, later research has shown that the tibia can also fail in tension, which Equation 6 fails to represent, and that the Hybrid III crash dummy's tibia does not accurately measure the forces.

$$
T I=\frac{F}{F_{C}} \cdot \frac{M}{M_{C}} \cdot 1.3
$$

For the thigh, the injury risk is a function of the axial force on the femur, $\mathrm{F}(\mathrm{kN})$, shown in Equation 7 (Eppinger, et al., 1999) It is plotted below in Figure 7.

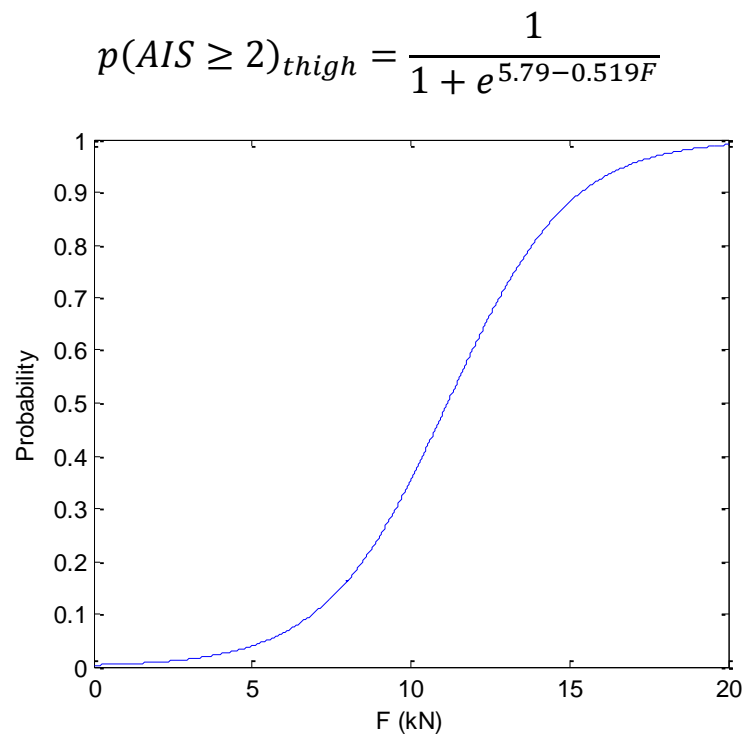

\section{Figure 7 - Thigh AIS 2+ injury probability curve}

Due to the complexity of leg injuries, reliable injury risk functions are very difficult to generate and as such are only available for AIS 2+. Funk et al. (2002) developed a risk function for the foot/ankle complex by testing cadaveric samples under different values of Achilles tension. When the function is evaluated for a 45 -year-old $50^{\text {th }}$ percentile male, the equation reduces to Equation 8, below, where $\mathrm{T}$ is the tibia axial force in N. Figure 8 shows the probability curve graphically.

$$
p(A I S \geq 2)_{\text {lower leg }}=1-e^{-\exp (4.99 \ln T-45.412)}
$$




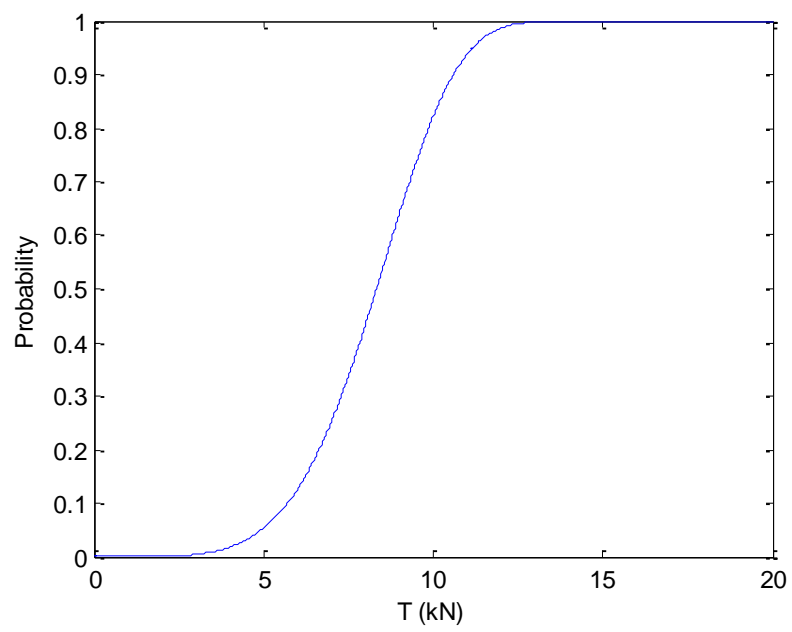

Figure 8 - Leg AIS 2+ injury probability curve

Injuries to the ankle and foot (specifically the calcaneus, talus, ankle, and midfoot fractures) can also be predicted using Equation 9, which is more frequently cited in the literature than Equation 8, where $\mathrm{T}$ is the axial force in the tibia in N (Kuppa, Wang, Haffner, \& Eppinger, 2001). Injuries to the calcaneus and talus in particular, which are situated in the heel of the foot and take the brunt of a tibial axial force, represent some of the most severe injuries to the lower extremities (Funk, 2002). The probability curve for this equation is shown in Figure 9.

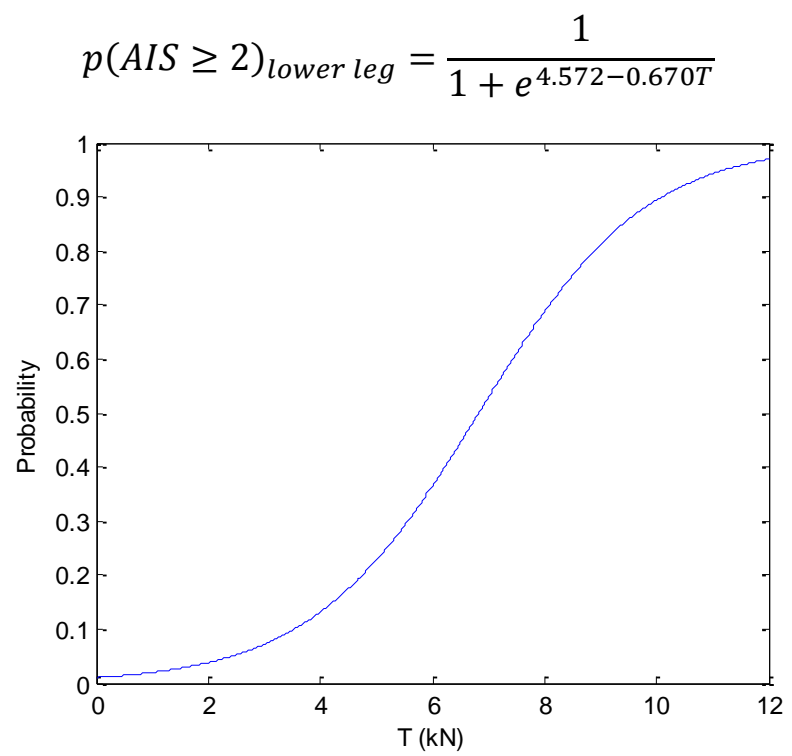

Figure 9 - Ankle and foot AIS 2+ injury probability curve 


\subsubsection{WHIPLASH}

To measure whiplash injuries in rear impact crashes, the neck injury criterion (NIC) is used. Whiplash injuries are AIS1, but they are common and can produce painful, long-term symptoms. The NIC uses the acceleration and velocity of the head relative to the T1 vertebra at the base of the neck. NIC is calculated as shown in the equation set below (Boström, 1996). The maximum value over the course of the crash is taken to determine the probability of whiplash.

$$
\begin{gathered}
\text { NIC }=a_{r e l} \cdot 0.2+v_{r e l}^{2} \\
a_{r e l}=a_{x}^{T 1}-a_{x}{ }^{\text {head }} \\
v_{r e l}=\int a_{r e l} d t
\end{gathered}
$$

There is not a widely used logistically derived injury risk function for whiplash injuries, but a suitable alternative is shown in Figure 10 below for injuries with symptoms lasting more than one month (Kullgren, Eriksson, Bostrom, \& Krafft, 2005). The $\mathrm{NIC}_{\max }$ was measured for real-life crashes that were reconstructed in MADYMO, but with the small sample a logistic regression was not performed. Instead, values may be approximated from the graph.

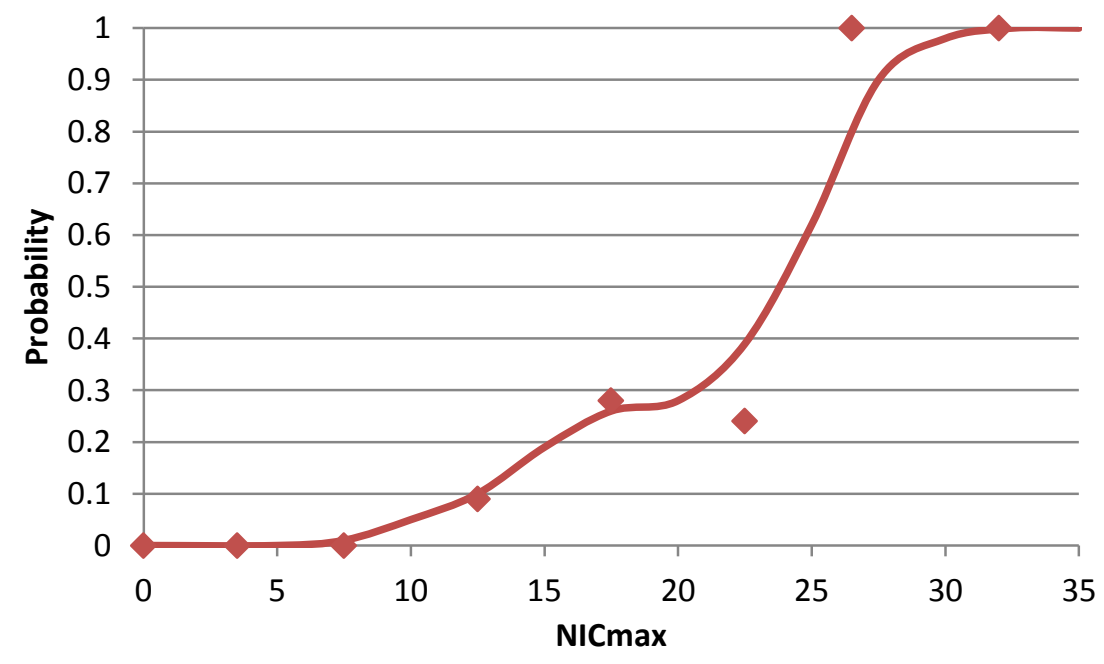

Figure 10 - Whiplash injury risk function

\subsubsection{WhOle BOdy INJURY METRIC}

The whole-body injury metric (WBIM) was developed to give an aggregate description of injury potential through a weighted combination of injuries to the head, neck, torso, and legs (Bose, 2008). Injury probabilities are calculated for each AIS level of injury and the societal cost for each injury is formulated 
by a sum of medical costs and quality of life costs. The non-medical costs aim to quantify the effects of long-term impairments, which are particularly significant in differentiating the severities of head and neck injuries.

The components of the model are the five standard injury metrics: head injury criterion (HIC), normalized neck injury criterion $\left(\mathrm{N}_{\mathrm{ij}}\right)$, chest displacement $\left(\mathrm{c}_{\mathrm{disp}}\right)$, femur load $(\mathrm{fem})$, and tibial load $\left(\mathrm{tib}_{1}\right)$. These are scaled to the $50^{\text {th }}$ percentile adult male because the injury risk functions are built for that group. The probability of injury is determined for each area from the corresponding injury risk function for the desired AIS. These values are weighted by the medical and quality of life costs to determine the whole body injury cost (WIC).

The monetary weights allow for injuries in different areas of the body to be considered separately. However, because the injuries used to create these numbers were coded by the worst injury sustained, i.e., MAIS, costs associated with lower-level injuries are also included. Thus, if the model is used to sum the costs associated with injuries from the whole body, some costs will be double-counted. This is circumvented by normalizing the whole body injury cost (WIC) using the minimum cost value for each injury metric $\left(\mathrm{WIC}_{\min }\right.$ ) of $\$ 100,000$ and the maximum cost using threshold values for the $50^{\text {th }}$ percentile male dummy ( $\mathrm{WIC}_{50 \%}$ ) of $\$ 652,000$ (Adam, 2011). The calculation for the WBIM is shown in Equation 11.

$$
W B I M=\frac{W I C-W I C_{\min }}{W I C_{50 \%}-W I C_{\min }}
$$

The key limitations of the WBIM are the over prediction of costs due to MAIS injury reporting and the fact that the individual injury metrics do not account for all cases. This is seen in particular in the lower extremities, as curves have only been developed for AIS 2+ (Adam, 2011). Because this research focuses on comparison of the WBIM, the over prediction of costs should be mitigated. The focus remains on AIS 2 injuries as well, so the concerns with under prediction of injuries are not applicable. 


\section{CHAPTER 3: STUDY CORRIDOR}

\subsection{ROUTE 50 NETWORK}

For the study, a 6.1 mile section of Route 50 (Lee Jackson Memorial Highway) in Northern Virginia between the intersections with Pleasant Valley Rd. and Rugby Rd was chosen for analysis. It is a welltraveled, six-lane divided urban collector road. There are 16 intersections with coordinated-actuated signals and one interchange along the stretch. Volume data was obtained from video cameras at the beginning and end of the corridor, and turning movements and the existing timing plan were obtained from the Northern Region Operation database (Park \& Lee, 2009).

For simulation and comparison, the midmorning period was chosen for analysis, from 9 AM to 12 PM. This encompassed sufficient vehicle traffic to perform analysis while avoiding complications from the morning rush hour period.

\subsection{CRASH DATA}

For validation, crash data for the segment was obtained from VDOT for 9 AM to 12 PM from 2007 to 2009. This encompassed both segment and intersection crashes between Pleasant Valley and Rugby Roads, but is limited to mainline crashes coded to Route 50. There were a total of 641 crashes in those three years, 72 of which occurred from 9 AM - 12 PM. The crashes during the summary period are summarized in Table 2.

Table 2 - Rte. 50 Crashes, 9AM-12PM

\begin{tabular}{lrrr}
\hline \multicolumn{1}{c}{ Crash Type } & Injury & $\begin{array}{c}\text { Property } \\
\text { Damage Only }\end{array}$ & Total \\
\hline Rear-end & 24 & 35 & 59 \\
Angle & 2 & 6 & 8 \\
Sideswipe (same & 3 & 9 & 12 \\
direction) & 1 & & 1 \\
Fixed object off road & & 1 & 1 \\
Other & $\mathbf{3 0}$ & $\mathbf{5 1}$ & $\mathbf{8 2}$ \\
\hline Grand Total & & & \\
\hline
\end{tabular}

To better compare crashes and conflicts, SSAM's three categories needed to be paired with crash types as coded in the police reports. First, the crashes were filtered for multiple-vehicle crashes. Rear-end conflicts clearly correspond to rear-end crashes. Crossing crashes correspond best to angle crashes, as they frequently occur in the middle of intersections and involve the front of the offending vehicle. Lane change conflicts are closest to same direction sideswipe crashes. 
There were no opposite-direction crashes in the study period and only four head-on crashes. Head-on crashes would be considered crossing conflicts, but they arise from extreme situations that would not be represented in simulation. The other crash types that were not accounted for in the simulation included collisions with deer, pedestrians, and cyclists.

Rear-end crashes were selected for further evaluation and comparison due to the relative simplicity of their crash dynamics. Rear-end crashes accounted for $72.2 \%$ of the total crashes that correspond to conflicts in the time period of interest, with 52 incidents. There were 12 sideswipe crashes (16.7\%) and 8 angle crashes $(11.1 \%)$. 28 of these crashes were injury crashes and 44 were property damage only.

Of the rear-end crashes, 28 (47\%) were caused by driver inattention or error and 29 (49\%) had a miscellaneous cause, which can be anything from avoiding an animal to loss of part of a load. Of the remaining crashes, one was caused by a speeding driver, one by a defective vehicle, and one by a slick road. The angle and sideswipe crashes were all caused by driver inattention or miscellaneous factors.

Injury data for the rear-end crashes were obtained from VDOT to compare against the results from MADYMO. There were 23 injury crashes in the period of interest and one fatality. The fatal crash was listed as a passenger on a garbage truck, who was likely standing on the back, so this data point was discarded as an anomalous event. Injuries were coded on the KABCO scale, where K represents a fatality; $\mathrm{A}, \mathrm{B}$, and $\mathrm{C}$ represent injuries; and $\mathrm{O}$ represents property damage only. All rear-end crashes are summarized in Figure 11, where multiple-injury crashes are coded by the maximum injury level.

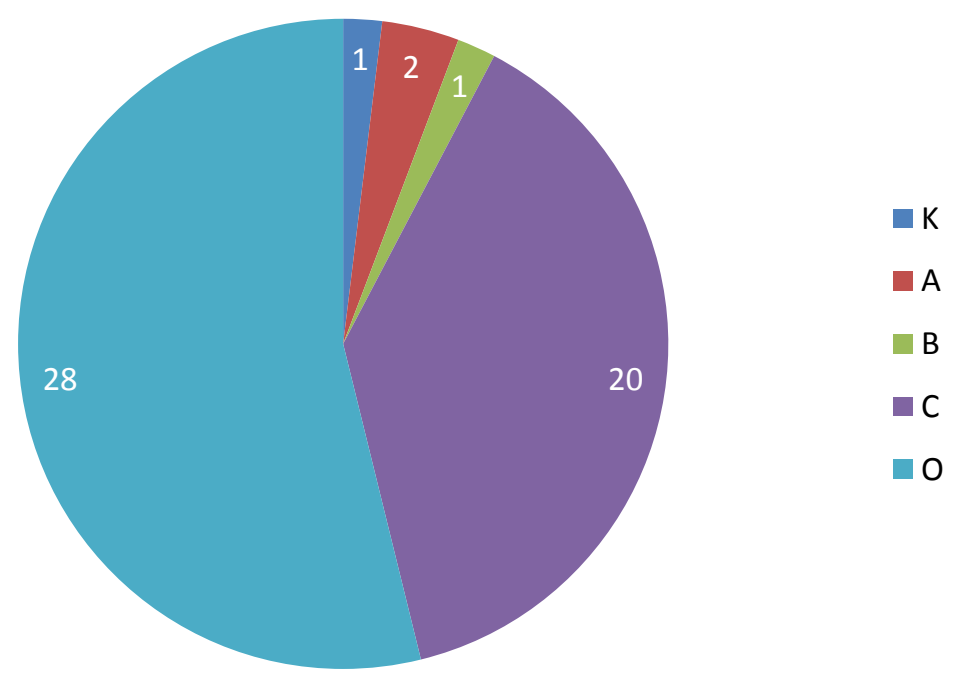

Figure 11 - Rear-end crash summary 
The injury scale ranges from $\mathrm{C}$, which is a possible low-level injury that is not evident to the reporting officer at the crash site to A, which is a clearly evident, incapacitating injury that threatens the victim's day-to-day life. B injuries are evident but non-incapacitating. Whiplash is frequently a C-level injury, as it is not evident to the reporting police officer but is a frequent result of rear-end crashes.

The 23 at-fault drivers ranged in age from 21 to 63 and were evenly split between male and female. Four of these drivers sustained C-level injuries and one sustained A-level injuries. Of the front vehicles, 18 of the drivers sustained C-level injuries, most likely whiplash, one had B-level injuries, and one had A-level injuries. Two passengers in different crashes also sustained C-level injuries. Seven of these crashes also involved a third car, but only two of them had an injury in that vehicle, and both were C-level.

\subsection{DATA AGGREGATION}

The corridor was selected for analysis rather than a single intersection in order to maximize the amount of data collected and simulated. At the same time, it avoids creating a false impression of the accuracy of the proposed method. Conflicts may not directly correlate to crashes and cannot act as a straight predictor of crashes, and a smaller granularity would tempt such comparisons. 


\section{CHAPTER 4: VISSIM/SSAM INTEGRATION}

\subsection{SIMULATION SETUP}

The corridor for study had already been built in VISSIM by another group for research on optimizing coordinated actuated signals (Park \& Lee, 2009). The mainline road, sixteen cross streets, and an interchange are represented in the model, which is shown in Figure 12. For simplicity, parking lots and driveways for businesses are not included in the model.

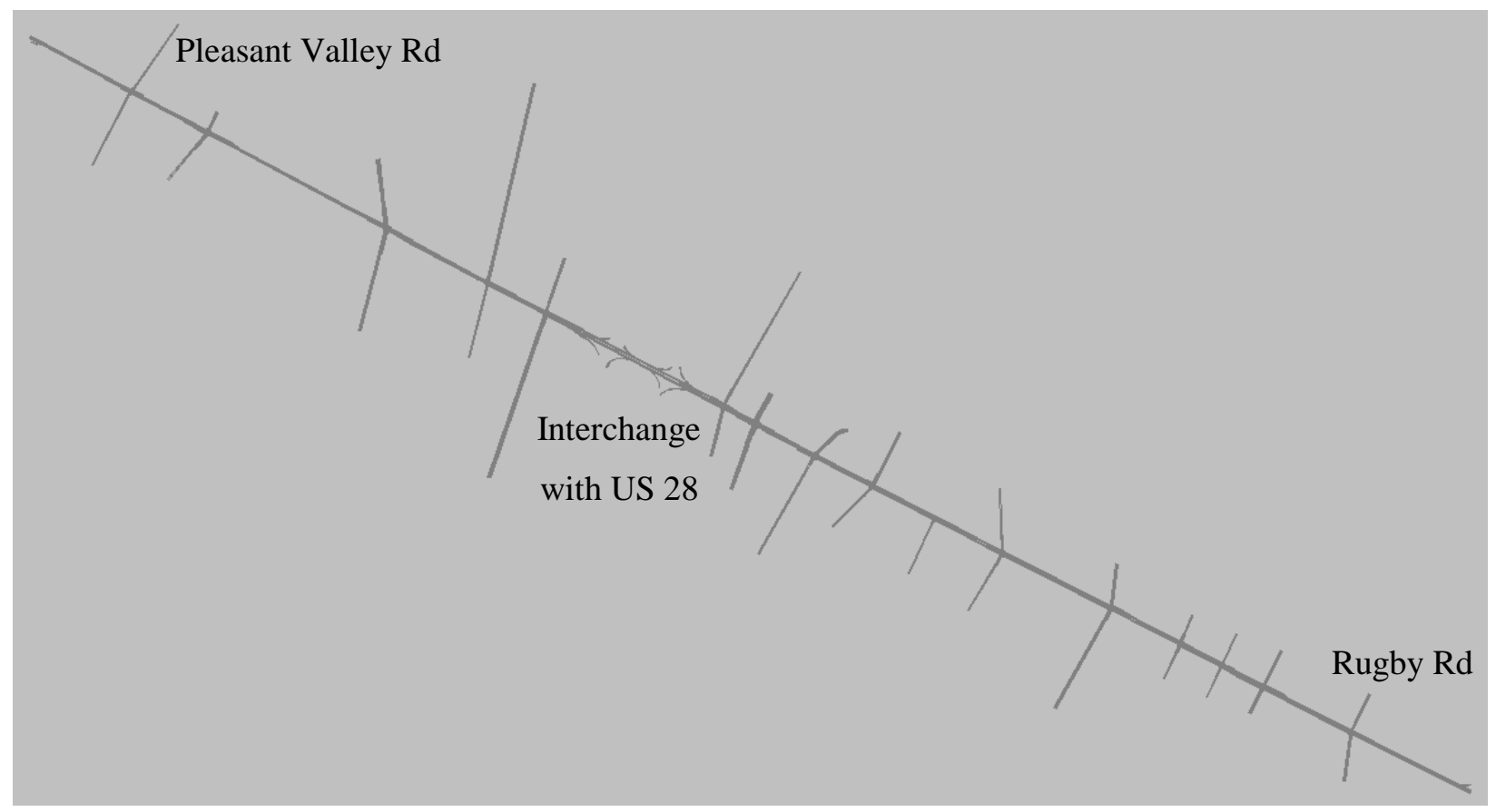

Figure 12 - Rt. 50 in VISSIM

The coordinated-actuated signals are implemented using Ring Barrier Controllers and detectors placed on the links. They were already optimized as a part of the previous study.

Each simulation is run with a random seed to control the stochastic processes. These seeds were noted so that comparison trials could use the same seed for more faithful comparison. For each simulation, a trajectory file is output, which is a specialized file format for SSAM that contains information on the trajectories of all vehicles. 


\subsection{CONFLICT ANALYSIS IN SSAM}

Each trajectory file was opened in SSAM and analyzed using a TTC $<2.5 \mathrm{~s}$ and a PET $<9.98 \mathrm{~s}$. SSAM reviews the trajectory files to find conflicts that meet the criteria and produces metrics for them.

The conflict data was exported to Excel for further manipulation and the DRD threshold of $15 \mathrm{ft} / \mathrm{s}^{2}$ (4.5 $\mathrm{m} / \mathrm{s}^{2}$ ) was applied. All conflicts with a TTC of zero were removed, as these represent situations in VISSIM where two vehicles overlap due to the definition of the conflict zones. While fixing the priority rules can alleviate these occurrences, some conflicts are generated by abrupt lane changes as vehicles enter the network and when vehicles fail to yield to a priority rule (Huang, 2013). As these do not reflect crashes in any way, they are removed from analysis.

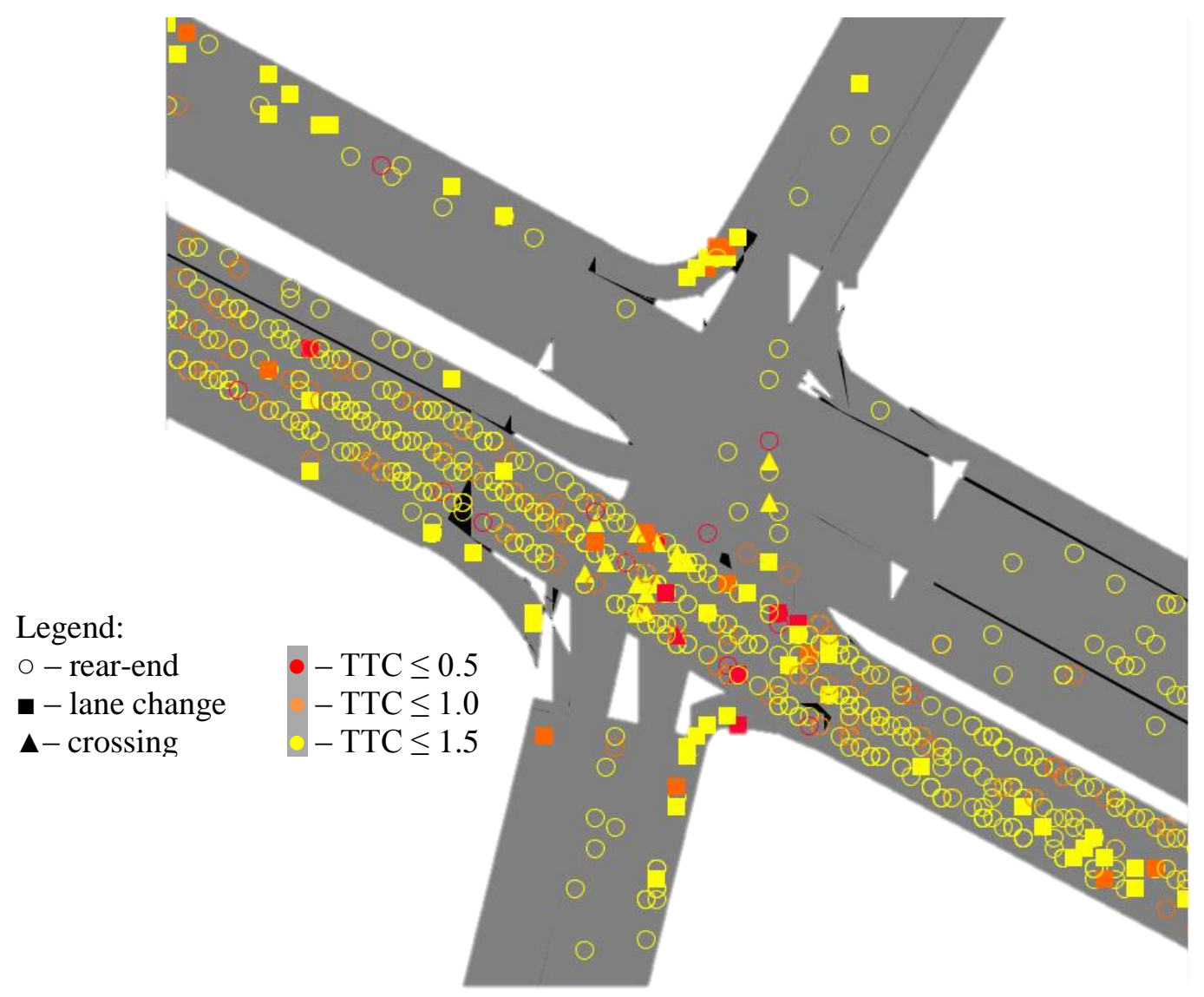

Figure 13 - Conflict Display in SSAM

Figure 13 above shows a mapping of conflict locations for one three-hour run before the DRD threshold is applied at the intersection of Route 50 and Centreville $\mathrm{Rd}$. The proliferation of rear-end conflicts can be seen, particularly in the eastbound direction. There are a number of lane change conflicts in the right hand 
turns and a few crossing conflicts in the intersection. This visualization tool aids in hotspot analysis as well.

Five simulations were run with VISSIM for analysis. Initial conflict results are summarized in Table 3. There were surprisingly few crossing conflicts that met both the TTC and DRD thresholds, with four runs having one each and one seeing none. Rear-end conflicts accounted for $70 \%$ of the total number of conflicts, which is not surprising on a signalized urban corridor. By average TTC, the rear-end conflicts were the least severe. Many of these take place as cars are slowing to stop at a light. The DRD ranges from the threshold of $-4.5 \mathrm{~m} / \mathrm{s}^{2}$ to $-12.49 \mathrm{~m} / \mathrm{s}^{2}$ in the most extreme crossing case. For rear-ends, the largest DRD seen is $-11.12 \mathrm{~m} / \mathrm{s}^{2}$.

Table 3 - Summary of Conflicts

\begin{tabular}{lrrrrr}
\hline Conflict Type & $\begin{array}{c}\text { Count } \\
\text { Crossing }\end{array}$ & $\begin{array}{c}\text { Average of TTC } \\
(\mathbf{s})\end{array}$ & $\begin{array}{c}\text { Min of DRD } \\
\left(\mathbf{m} / \mathbf{s}^{\mathbf{2}}\right)\end{array}$ & $\begin{array}{c}\text { Max of DRD } \\
\left(\mathbf{m} / \mathbf{s}^{\mathbf{2}}\right)\end{array}$ & $\begin{array}{c}\text { Average of DRD } \\
\left(\mathbf{m} / \mathbf{s}^{\mathbf{2}}\right)\end{array}$ \\
\hline Lane change & 4 & 1.250 & -4.782 & -12.49 & -6.840 \\
Rear-end & 354 & 1.176 & -4.509 & -10.758 & -6.372 \\
Total & 857 & 1.487 & -4.505 & -11.117 & -6.479 \\
\hline
\end{tabular}




\section{CHAPTER 5: MADYMO RESULTS}

MADYMO is a vehicle dynamics simulator that is used to determine the forces on occupants during a crash. For ease of initial integration, rear-end conflicts were chosen for analysis. These conflicts happen in a very similar way each time and required only three models to be constructed.

\subsection{OCCUPANT MODELS}

Three occupant models were used for analysis: front impact without airbag, front impact with airbag (Hybrid III), and rear impact (BioRID II), shown in Figure 14. These models are based off of eponymous crash test dummies, which are standard in industry. The Hybrid III, originally developed by General Motors, is the most widely used crash test dummy for frontal impact testing (Humanetics ATD, 2014).

The BioRID II (Biofidelic Rear Impact Dummy) is a modified version of the Hybrid III, using 24 separate vertebrae to better model injuries from rear-end crashes (Humanetics ATD, 2014). The models also incorporated the seat, headrest, restraints, and, in the case of the front impact, the steering column. Both dummies used were the $50^{\text {th }}$ percentile male, as that is the standard for all injury criterion and probability curves.

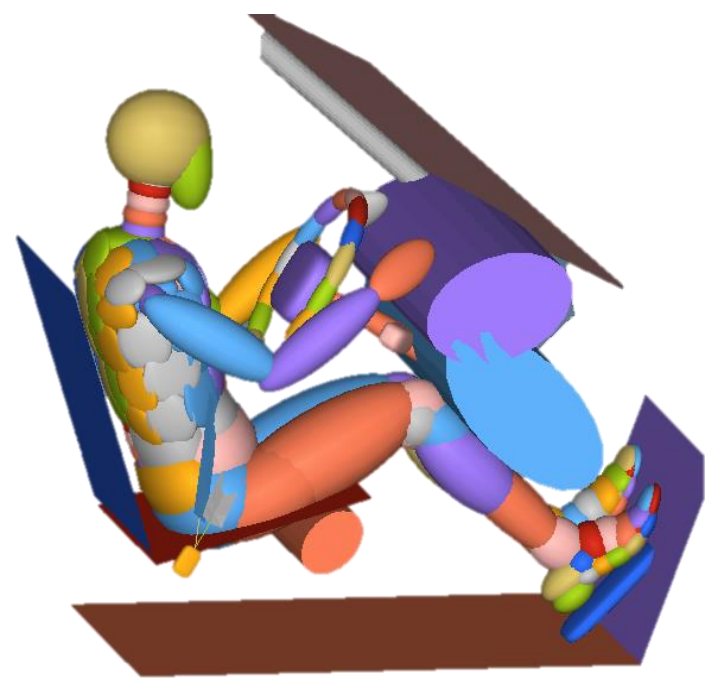

(a)

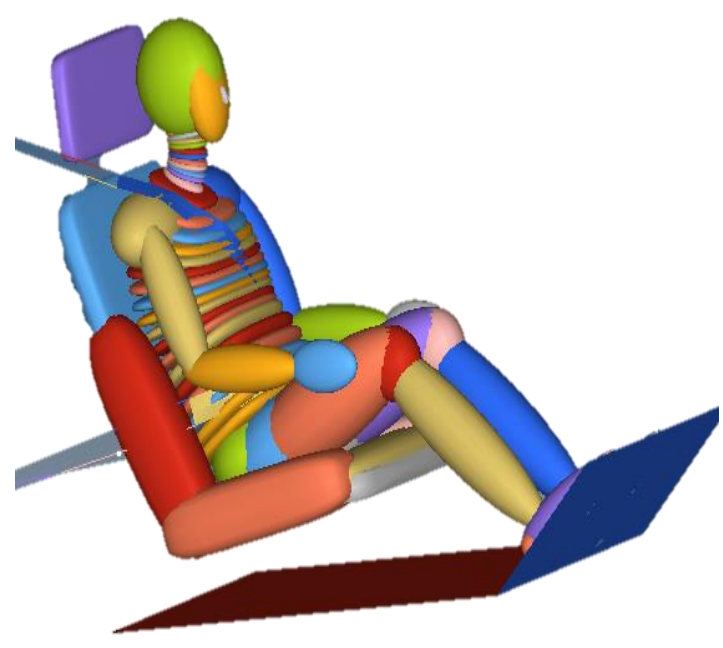

(b)

Figure 14 - Occupant Models: a) Hybrid III b) BioRID II

Because it is impossible for auto makers to ensure that an airbag will properly deploy at a certain speed, the United States does not have any regulation to that effect. However, it is an accepted rule of thumb in the crash-testing industry that the airbag deploys at crashes with a velocity differential around $14 \mathrm{mph}$ or 
$23 \mathrm{kph}$. To model a two-car crash, it is considered equivalent to a collision with a static barrier at twice the speed difference, so the airbag will not deploy when the differential is under $46 \mathrm{kph}$. Figure 15 below shows the Hybrid III model with the airbag deployed.

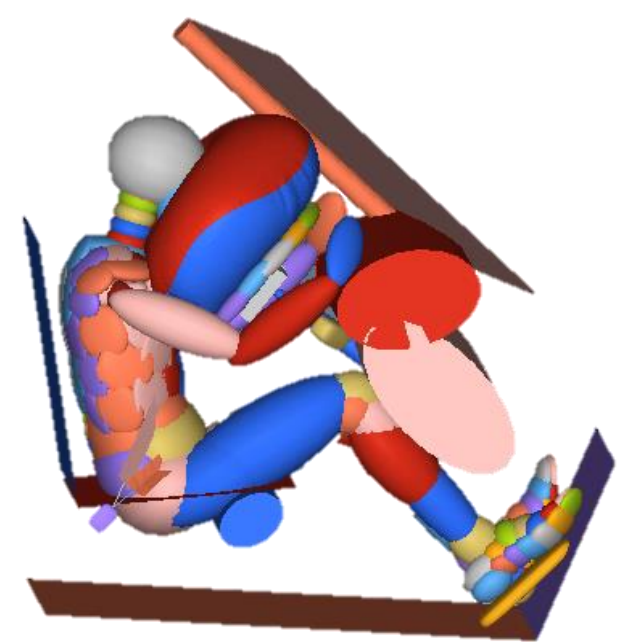

Figure 15 - Hybrid III occupant model with airbag deployed

\subsection{TRANSLATING CONFLICTS TO CRASHES}

In order to analyze conflicts, which contained no impact due to the nature of VISSIM simulation, a crash trajectory had to be assumed. To construct theoretical crashes, the trajectories were extended from the point of minimum TTC, assuming deceleration rate and heading remained constant, until they collided at $t=0$. Finally, the leading vehicle's velocity was subtracted from the following vehicle's velocity in order to calculate the velocity differential at impact.

Lacking other specific information about the theoretical crash, the research team decided to assume standard values for other variables. MADYMO uses a standard crash pulse (Figure 16) for frontal impact crashes, which was scaled appropriately to reflect the conflicts being simulated (TASS, 2013). Standard values were also assumed for occupant position, vehicle type (standard mid-size sedan), seat belt use, etc. 


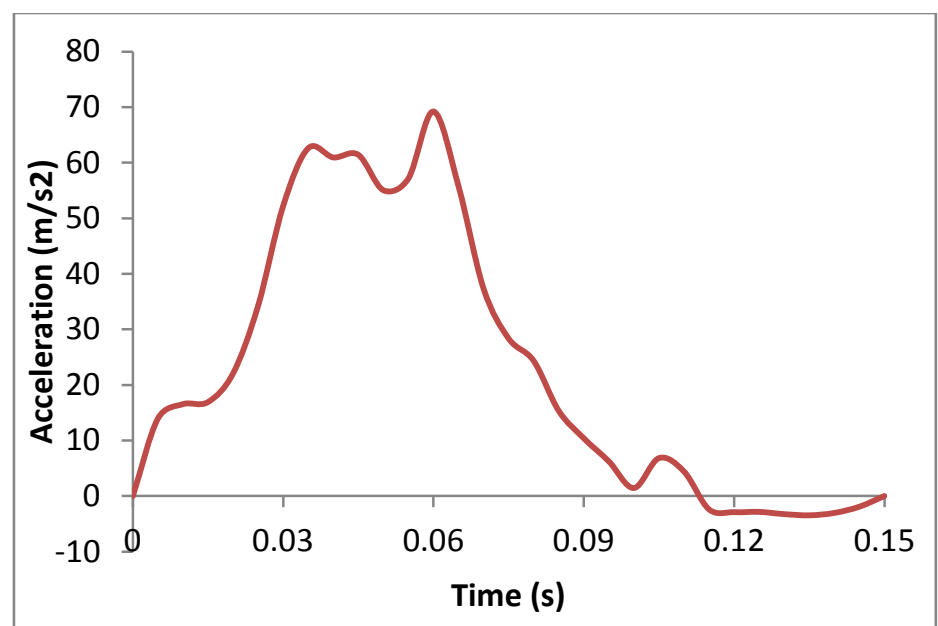

Figure 16 - Standard frontal crash impulse

MADYMO simulations of both the leading and following cars were run for a couple of example conflicts, and determined that no parameters other than the velocity differential would be changed. MADYMO output forces on the occupants for each major region, i.e., the head, neck, torso, upper and lower legs, that can then be used to calculate injury criteria.

\subsubsection{INJURY PROBABILITY FUNCTIONS}

Injury probability functions are used to translate forces simulated on each body part into a probability of injury. The original probability functions reviewed in Section 2.3.2 are based on logistic regressions with the exception of the lower extremities. The logistic function is not able to reach 0 for the low levels of $\mathrm{N}_{\mathrm{ij}}$ and $\mathrm{C}_{\text {disp }}$ (or $\left.\mathrm{D}_{\max }\right)$ that are experienced in this study. To obtain more accurate modeling at these values, the logistic models were converted to Weibull distributions. A comparison of the two can be seen in Figure 17, which demonstrates the differing behavior of the two distributions at extreme values. 


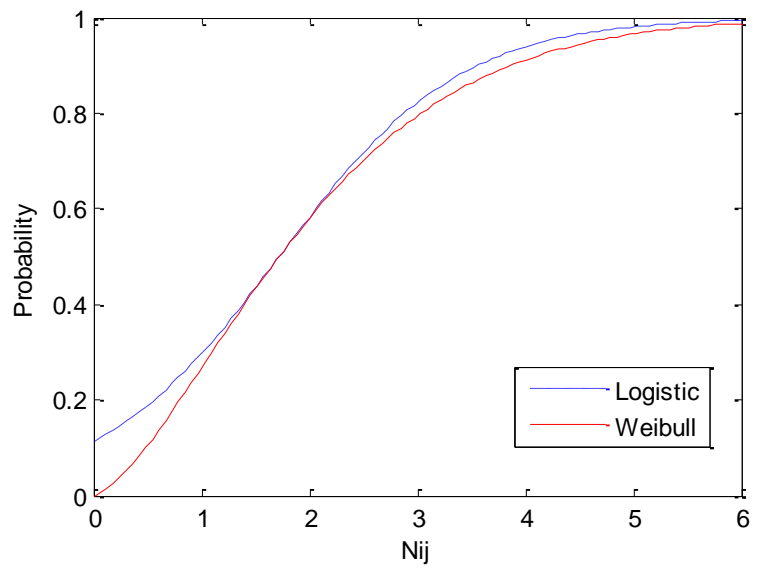

(a)

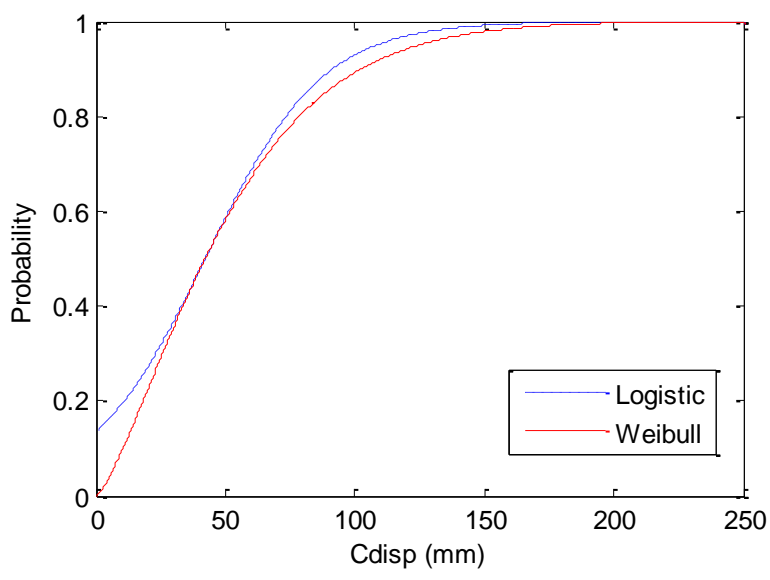

(b)

Figure 17 - Logistic vs. Weibull Distributions for a) neck injuries and b) chest injuries

To convert the logistic model to a Weibull model, it was assumed that the value and slope at 50\% probability of injury were equal. This gives two equations to solve for the two parameters of the Weibull distribution. More detail on this process can be found in Appendix A. This conversion was performed for the neck and thorax AIS 2 risk functions to better capture behavior at low applied forces. The final injury risk functions used for the project are given in Table 4. The whiplash injury risks were read from the graph in Figure 10, given on page 16. The AIS risk functions were described in detail in Chapter 2.

Table 4 - Injury Risk Functions

\begin{tabular}{|l|l|c|c|}
\hline \multicolumn{1}{|c|}{$\begin{array}{c}\text { Severity } \\
\text { Level }\end{array}$} & \multicolumn{1}{|c|}{ Injury Region } & Risk Function & Distribution \\
\hline AIS 1 & Neck (whiplash) & Graph, Figure 10 & N/A \\
\hline AIS 2 & Head & $\frac{1}{1+e^{200 / H I C+2.49-.0048 H I C}}$ & Logistic \\
\cline { 2 - 4 } & Neck & $1-\exp \left[-\left(\frac{N_{i j}}{2.20122}\right)^{1.4816478}\right]$ & Weibull \\
\cline { 2 - 4 } & Thorax & $1-\exp \left[-\left(\frac{C_{d i s p}}{55.2916}\right)^{1.349}\right]$ & Weibull \\
\cline { 2 - 4 } & Upper Leg & $\frac{1}{1+e^{5.79-0.519 F_{f}}}$ & Logistic \\
\cline { 2 - 4 } & Lower Leg & $\frac{1}{1+e^{4.572-0.67 T_{f}}}$ & Logistic \\
\hline
\end{tabular}




\subsection{VALIDATION AGAINST INJURY DATA}

To validate the method, the injury probabilities extracted from MADYMO were compared to the injury data from the police reports. Without access to specifics about the crashes like the conflicting speed, however, all crashes and conflicts had to be compared as a group. More accurate statistical comparisons are also not possible without more data on the injury crashes.

At the speeds on the corridor, there are very few injuries expected of rear-end crashes. The injuries sustained in the 23 real-world rear-end crashes are summarized in Table 5. Whiplash injuries in the leading vehicle are the most common (20), counting both drivers and passengers. Only two cases had A or B level injuries. The following vehicle rarely saw injuries, and only saw high-severity injuries in one case.

Table 5 - Rear-End Crash Injuries

\begin{tabular}{l|c|r|} 
Car & Injury Level & Number \\
\hline \multirow{2}{*}{ Following (striking) } & $\mathrm{A}$ & 1 \\
\cline { 2 - 3 } & $\mathrm{C}$ & 4 \\
\hline \multirow{3}{*}{ Leading } & $\mathrm{A}$ & 1 \\
\cline { 2 - 3 } & $\mathrm{B}$ & 1 \\
\cline { 2 - 3 } & $\mathrm{C}$ & 20
\end{tabular}

The simulated conflicts in the five simulation runs had similar trends. The injury probabilities calculated for these conflicts are summarized in Table 6 , separated by trial. The average probability of whiplash across all of the trials was $35.6 \%$ of cases. 20 out of 59 rear-end crashes (33.9\%) saw C-level injury in the leading car, which corresponds to whiplash injury.

Table 6 - Conflict Injury Average Probabilities

\begin{tabular}{crrrrr}
\hline Trial & \multicolumn{1}{c}{ Count } & Whiplash & Neck AIS2+ & Thigh AIS2+ & Lower Leg AIS2+ \\
\hline $\mathbf{1}$ & 184 & 0.344 & 0.008 & 0.004 & 0.024 \\
$\mathbf{2}$ & 174 & 0.302 & 0.008 & 0.004 & 0.021 \\
$\mathbf{3}$ & 163 & 0.468 & 0.008 & 0.004 & 0.026 \\
$\mathbf{4}$ & 179 & 0.344 & 0.008 & 0.004 & 0.023 \\
$\mathbf{5}$ & 157 & 0.329 & 0.009 & 0.004 & 0.022 \\
Total & $\mathbf{8 5 7}$ & $\mathbf{0 . 3 5 6}$ & $\mathbf{0 . 0 0 8}$ & $\mathbf{0 . 0 0 4}$ & $\mathbf{0 . 0 2 3}$ \\
\hline
\end{tabular}

Similarly, 5 out of 59 crashes $(8.47 \%)$ of the striking vehicles experienced injuries. Making the simplifying assumption that the injury probabilities for the following car are independent, the probability 
of an injury is $3.5 \%$. While this comparison is less favorable than that for whiplash, it is on the same order of magnitude and is subject to more assumptions.

For both the leading and following car, the proportion of simulated crashes with injuries appears reasonable. The number of $\mathrm{C}$-level injuries in the real-world data supports the decision to use AIS 2+ injury curves, as very few serious injuries result from these crashes.

\subsection{WHOLE-BODY INJURY METRIC}

In order to get an overall picture of the injury severity of a crash, the research team decided to use the Whole Body Injury Metric (WBIM), a weighted average of injury probabilities and societal costs. For AIS 2 injuries, used for the striking car in each crash, the weighting factors are described in Table 7.

Table 7 - WBIM Weighting Factors, AIS2 (Bose, 2008)

\begin{tabular}{|l|r|r|r|}
\hline \multicolumn{1}{|c|}{ Body Region } & Medical Costs & Quality of Life & Comprehensive \\
\hline Head & 59911 & 198139 & 258050 \\
\hline Neck & 49841 & 40165 & 90006 \\
\hline Chest & 58168 & 52173 & 110341 \\
\hline Thigh & 54259 & 44555 & 98814 \\
\hline Leg/foot & 54259 & 44555 & 98814 \\
\hline
\end{tabular}

When these monetary weighting factors are used in conjunction with the injury probabilities, the weighted injury cost (WIC) becomes:

$$
\begin{gathered}
W I C=258050 p(\text { head })+90006 p(\text { neck })+110341 p(\text { chest }) \\
+98814[p(\text { thigh })+p(\text { leg } / \text { foot })]
\end{gathered}
$$

This shows that head injuries are considered the most important due to considerable quality of life costs, while all other injuries are of similar weight. To calculate the WBIM and account for over prediction of costs due to multiple injury counting, the WIC must be normalized to the minimum and maximum possible injury costs. According to Adam (2011), for the $50^{\text {th }}$ percentile male, this equation becomes

$$
W B I M=\frac{W I C-100,000}{652,000-100,000}
$$


However, when applied to data from our research, the WBIM becomes negative, due to the very low chance of injury in the studied crashes, leaving the WIC below the hypothetical minimum cited. Without further data to calculate a minimum cost for this application, the cost coefficients were instead normalized to the coefficient total to create the $\mathrm{WIC}^{\prime}$, which will always be between 0 and 1 . This formulation still allows for comparison between crashes, mitigating the effects of over-counting injuries, and removes the relation to cost.

$$
\begin{gathered}
W I C^{\prime}=0.39 p(\text { head })+0.14 p(\text { neck })+0.17 p(\text { chest }) \\
+0.15[p(\text { thigh })+p(\text { leg } / \text { foot })]
\end{gathered}
$$

\subsection{INJURY AND WBIM FUNCTIONS}

Due to the relative simplicity of rear-end crashes, the only variable that changed between simulated crashes was the velocity differential. To expedite analysis, functions were constructed relating velocity differential $\left(\mathrm{v}_{\text {diff }}\right)$ to injury probabilities and the overall WIC'. Crashes were simulated for velocity differentials of $10 \mathrm{kph}$, five-kph intervals from 20 to 45, 46 (for airbag deployment), 50, and 60. Regressions were fit to the data using Excel and were found to have very high $\mathrm{R}^{2}$ values. The resulting formulae are summarized in Table 8 below. The data and graphs can be found in Appendix B.

\begin{tabular}{|c|c|c|c|}
\hline Independent Variable & Equation & $\overline{\mathbf{R}^{2}}$ & Fit Type \\
\hline Neck AIS1 (Whiplash) & $0.0018 v_{\text {diff }}^{2}-.0203 v_{\text {diff }}+.0256$ & 0.9993 & Quadratic \\
\hline Neck AIS2 & $0.0007 v_{\text {diff }}-0.0036 ; v_{\text {diff }}<46 \mathrm{kph}$ & 0.9920 & Linear \\
\hline Thigh AIS2 & $\begin{array}{c}-3 \cdot 10^{-8} * v_{d i f f}^{3}+4 \cdot 10^{-6} * v_{d i f f}{ }^{2}-1 \cdot 10^{-4} \\
* v_{\text {diff }}+0.0044\end{array}$ & 0.9925 & Cubic \\
\hline Lower Leg AIS2 & $\begin{array}{c}8 \cdot 10^{-7} * v_{\text {diff }}^{3}-3 \cdot 10^{-5} * v_{\text {diff }}^{2} \\
+0.0007 v_{\text {diff }}+0.0083\end{array}$ & 0.9925 & Cubic \\
\hline $\mathrm{WIC}^{\prime}$ & $0.0021 e^{0.0387 v_{d i f f}}$ & 0.9948 & Exponential \\
\hline
\end{tabular}

Table 8 - Velocity Differential Injury Functions

There were no significant chances of a chest injury at the speeds tested, and head injuries were negligible, with only $0.05 \%$ occurrence at $\mathrm{v}_{\text {diff }}=60 \mathrm{kph}$. The neck injury AIS 2 risk experiences a change at $46 \mathrm{kph}$, 
where the airbag activates. The probability of injury drops from $2.72 \%$ to $2.33 \%$ and decreases to $2.27 \%$ by $\mathrm{v}_{\text {diff }}=60 \mathrm{kph}$. The $\mathrm{WIC}^{\prime}$, as an aggregate, also experiences a change due to airbag activation, but it is not significant enough to adjust the formula, especially with such a high $\mathrm{R}^{2}$.

All of these functions have very high $\mathrm{R}^{2}$ values, which gives great confidence in their results. A number of important variables were held constant for ease of analysis, including the occupant $\left(50^{\text {th }}\right.$ percentile male), seat position, acceleration, and crash pulse. Further analysis on these variables could be considered if they could be related to data from the microscopic simulation or study site. 


\section{CHAPTER 6: FRAMEWORK OVERVIEW}

\subsection{MODEL FLOW}

At the end of the process, the model flow moves simply from microscopic simulation in VISSIM to conflict analysis in SSAM, and finally crash dynamic simulation in MADYMO. For simple rear-end cases, the MADYMO step can be substituted with the appropriate equations relating $\mathrm{v}_{\text {diff }}$ to injury risk. The inputs and programs involved are summarized in Figure 18. Purple represents roadway factors, green stands for the driver, and blue denotes vehicle characteristics.

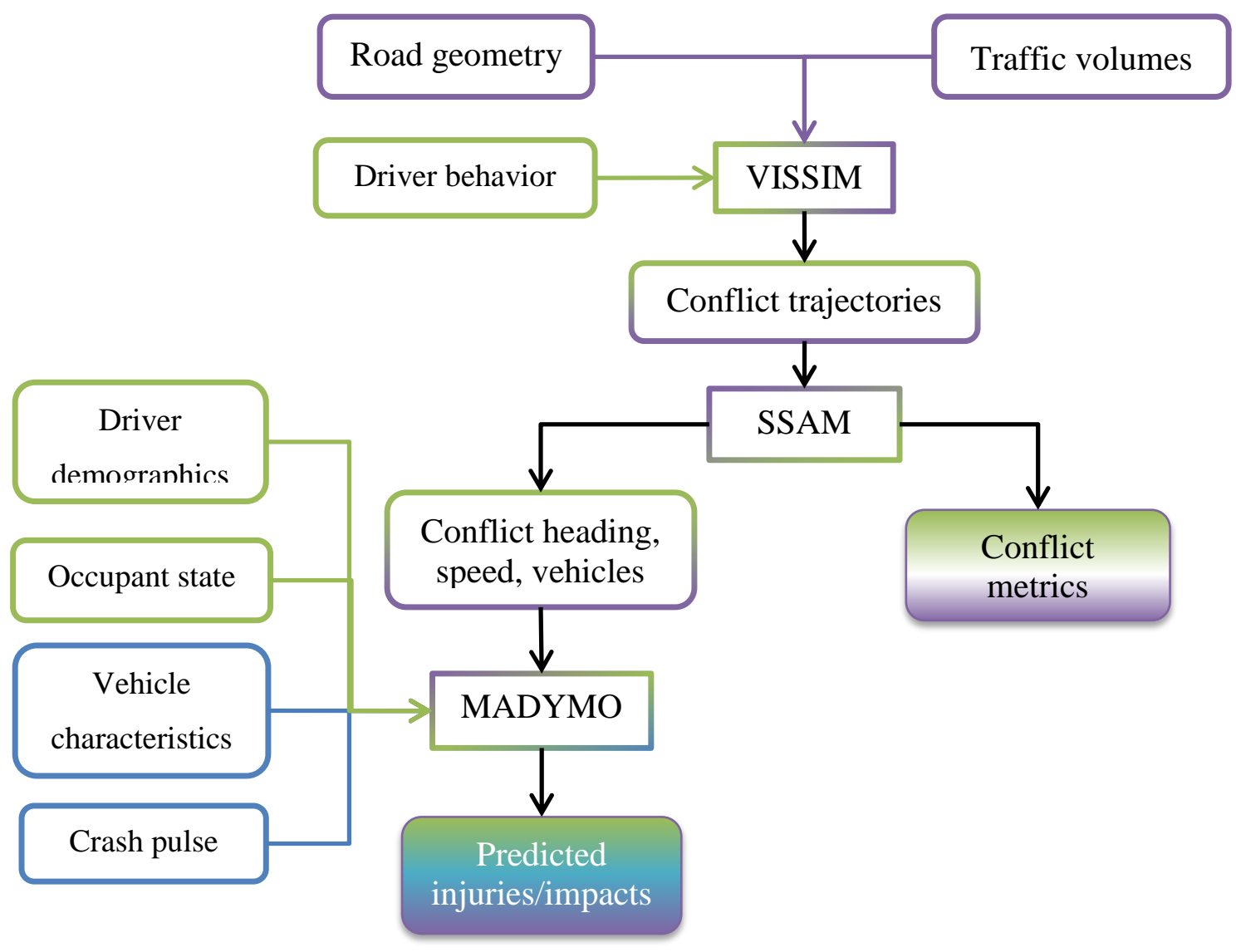

Figure 18 - Model Flowchart

The VISSIM command, or COM, interface can be used to automate VISSIM runs for ease of analysis, though SSAM analysis must be set up by hand. MADYMO analysis can also be easily scripted, and, as we have demonstrated, models can be developed if situational variables are held constant. 


\subsection{PROPOSED MODEL USES}

The purpose of the model is to create a more complete picture of safety, from the number, type, and locations of crashes to the injuries sustained therein. Due to limitations of microscopic traffic simulation, conflicts are used as a surrogate measure for crashes. Conflicts can be reliably compared to other conflicts, but reviewers must keep in mind that this model is not predictive nor is it directly related to crashes.

A number of parameters can be changed in VISSIM in order to test for safety efficacy. Infrastructure improvements can be easily added and some driving parameters can be changed to reflect in-vehicle technologies using the COM interface. Driver behavior such as gap acceptance can also be adjusted and tested for. By testing a proposed change against a base case, the number and type of conflicts can be studied as well as the injury risk they pose.

The use of the vehicle dynamics simulator also allows for inclusion of variables such as seat belt use, vehicle type, and occupant size. A wide variety of crash types can be studied once links are established between the SSAM data and the MADYMO inputs.

This framework is particularly useful to study the effect of policy decisions on transportation safety. Decisions such as requiring new in-vehicle safety technologies can be evaluated at differing levels of market penetration. Using VISSIM also allows for analysis of traffic flow, making this framework capable of spanning operations and safety. 


\section{CHAPTER 7: MODEL TESTING}

To demonstrate the capability of the model and show how data flows between the programs, the research team chose to study signal timing changes and forward collision warning. Limitations of the microscopic simulation made these tests difficult to complete, but the usefulness of the model is still demonstrated.

\subsection{SIGNAL TIMING}

The section of Route 50 used for analysis is a well-developed urban corridor. No intersection is wanting for turning lanes and the volume of the road would not call for expanded capacity. The signals in place are optimized coordinated-actuated signals, so there was very little that could be changed in the model from an infrastructure perspective. To test the model, the research team decided to change the yellow time, hypothesizing that a longer yellow may allow drivers to slow down more smoothly and avoid rearend collisions.

Each controller was changed to have a minimum of 5 seconds of yellow time. Most legs were already set to a yellow time of 4 seconds. Five runs with the same random seeds as the control data set were simulated in VISSIM and analyzed by SSAM. When compared to the control data set, however, no change in conflict numbers was found.

This can be attributed to a combination of the yellow lengthening being a minor adjustment in most phases as well as to VISSIM car modeling. The rear-end conflicts flagged by the program are related to normal slowing at the light and are not affected by the change in the yellow time. Driver-vehicle units make decisions rationally, proceeding through the light if they cannot stop at the bar, which is unaffected by the longer yellow. This is in contrast to human drivers, who may make poor judgments at yellow lights or take advantage of a yellow interval they know to be longer.

\subsection{FORWARD COLLISION WARNING}

Forward collision warning (FCW) and other pre-crash technologies are beginning to be implemented in passenger cars. An FCW system uses millimeter-wave radar or other sensors to warn the driver of an impending forward collision, allowing them to brake in time to avoid it. Some systems, such as pre-crash braking assist (PBA) and autonomous pre-crash braking (PB) also exist, which will either amplify driver braking or apply braking independently of driver input, respectively. These technologies should impact the occurrence and severity of rear-end collisions. 
Kusano and Gabler delved into pre-crash systems to determine the effectiveness of three integrated algorithms: FCW only, FCW and PBA, and FCW, PBA and PB (2012). They sampled 1396 real-world crashes from the National Automotive Sampling System/Crashworthiness Data System (NASS/CDS), which contain detailed records on approximately 5000 crashes per year, selected to be a representative sample of minor to severe collisions. Because the effectiveness of these systems is sensitive to the driver response, a distribution of driver reaction times was used from previous research and the timing of the warnings was based off of the TTC, with the first coming around $2.6 \mathrm{~s}$.

In order to implement this behavior in VISSIM, the drivers' perception-reaction time and braking behavior would need to be adjusted to match that modeled in the paper. While drivers have parameters meant to represent their aggression, VISSIM has no way to represent inattention well. The closest option is the driver sleep parameter, but when that is engaged the driver still engages in emergency braking. This behavior could not be changed within the base program in a way that would be consistent with real-world behavior. There have been driver behavior extensions written for the program, however, none of them were analyzed as a part of this research.

In lieu of being able to perform a simulation with pre-crash systems implemented, we used the results from the Kusano and Gabler study to describe the injury potential. Their results are summarized in Table 9 below.

Table 9 - Summary of Results from Kusano and Gabler, 2012

\begin{tabular}{lccc}
\hline Algorithm & $\begin{array}{c}\text { Percentage of } \\
\text { Crashes Prevented }\end{array}$ & $\begin{array}{c}\text { Median } \Delta \mathbf{V} \\
(\mathbf{k p h})\end{array}$ & $\begin{array}{c}\text { Percent Reduction } \\
\text { of Median } \Delta \mathbf{V}\end{array}$ \\
\hline No PCS & - & 17.0 & - \\
FCW & $3.2 \%$ & 14.7 & $14 \%$ \\
FCW + PBA & $3.6 \%$ & 13.0 & $24 \%$ \\
FCW + PBA + PB & $7.7 \%$ & 11.3 & $34 \%$ \\
\hline
\end{tabular}

These results were applied to the simulated conflicts to produce the data in Table 10. The percent reduction in $\Delta \mathrm{V}$ was applied to all cases, lacking more information to apply it more selectively. The table also details the effects of the $\Delta \mathrm{V}$ reduction to the injury probability. These numbers are very conservative compared to the authors' findings of $50 \%$ reduction with all systems implemented, which used a regression on $\Delta \mathrm{V}$ and seat belt use to determine an injury risk function. The authors note that their assumptions are generous and real-world benefits would likely be reduced (Kuppa, Wang, Haffner, \& Eppinger, 2001). 
Table 10 - Conflict Injury Probabilities for Pre-Crash Systems Cases

\begin{tabular}{lccccccc}
\hline Trial & $\begin{array}{c}\text { Median } \\
\mathbf{\Delta V}(\mathbf{k p h})\end{array}$ & Whiplash & $\begin{array}{c}\text { Neck } \\
\text { AIS2+ }\end{array}$ & $\begin{array}{c}\text { Thigh } \\
\text { AIS2+ }\end{array}$ & $\begin{array}{c}\text { Lower Leg } \\
\text { AIS2+ }\end{array}$ & WIC' $^{\prime}$ & $\begin{array}{c}\text { \%WIC }^{\prime} \\
\text { reduction }\end{array}$ \\
\hline $\begin{array}{l}\text { No PCS } \\
\text { control) }\end{array}$ & 15.39 & 0.158 & 0.007 & 0.004 & 0.017 & 0.0038 & - \\
FCW & 13.24 & 0.085 & 0.006 & 0.004 & 0.017 & 0.0035 & $8.00 \%$ \\
FCW+PBA & 11.70 & 0.046 & 0.005 & 0.004 & 0.017 & 0.0033 & $13.32 \%$ \\
FCW+PBA+PB & 10.16 & 0.026 & 0.004 & 0.004 & 0.018 & 0.0031 & $18.33 \%$ \\
\hline
\end{tabular}

While the microsimulation step had to be skipped, the probability curves derived from MADYMO make it simple to predict changes in injury risk. The injury risk is also reported by body region, allowing for more detailed analysis. Here, whiplash injuries see the most benefit, with a $46 \%$ reduction for FCW, $71 \%$ for FCW and PBA, and a total of $83.4 \%$ for the full pre-crash system. 


\section{CHAPTER 8: CONCLUSIONS AND RECOMMENDATIONS}

This project set out to create an interdisciplinary modeling environment to test the safety efficacy of infrastructure and vehicular improvements as a function of crash number, type, and injury severity. We have proven that such a framework can be built from existing models using VISSIM, SSAM, and MADYMO.

In the future, the model can be extended to cover other crash types, which would require more collaboration in order to faithfully represent the theoretical crashes in MADYMO, lacking many inputs. There will be more starting cases for both crossing and lane change conflicts, but it should be a straightforward extension of the work done to set up rear-end conflicts. The mapping of conflicts to crash types in this report is unrefined and should be revisited and refined before further work is done on the other two conflict types, which are less clear in the naming differences between crashes and conflicts. The model should be expanded to model corridors where geometric improvements may be applicable to reduce crash occurrence or injury.

The conflict method has a number of opponents, and with good rationale. There is no consensus as to how well conflicts represent crashes, although the comparison of conflicts to other conflicts has seemed favorable. This study was unable to obtain real-world conflict data for better validation and model calibration, but performance could be improved with such an effort. The thresholds selected for TTC and DRD could be studied further, particularly as the DRD finding was based in a small sample size and was not widely cited.

The greatest benefit to expanding upon this research would be an improvement in the microsimulator's representation of safety-critical driver behavior. Use of a driver model extension with VISSIM may allow for a wider variety of tests to be performed. Agent-based simulation is also a promising alternative. Better fidelity of driver behavior would allow for testing of new vehicle technologies that are prohibitively difficult to represent in programs like VISSIM.

Research with a similar goal was carried out by Sobhani, Young, and Sarvi that used statistical models to extend the capabilities of VISSIM's microscopic simulation (2013). After traffic flow is modeled in VISSIM, the driver reaction is determined as either reaction or no reaction through a model taking into account the speed limit and the interaction of weather, crash type, and gender. A general linear regression model then determines the $\Delta \mathrm{V}$ and kinetic energy of the crash, which uses the mass ratio of the vehicles 
and the interaction between the driver reaction and crash type. Finally, an injury severity score is determined by a model relating the kinetic energy and impact type of the crash.

While this research is similar to ours, each group took a different tactic. The statistical focus of the Sobhani model allows them better fidelity to crashes relating to their training data set, but is decoupled from the knowledge of crash dynamics gained by vehicle dynamics simulation that captures the human cost of crashes. This research can take away statistical options for accounting factors such as the weather and gender of the driver, which can be factored in through VISSIM's COM interface.

This research has demonstrated the potential for a simulation environment that covers the entirety of the transportation network, including the road, vehicles, and drivers, which will ultimately help the engineering field provide the best benefits to the public. Capturing these factors will contribute to better modeling and understanding of crashes and will allow researchers to study safety-critical situations in a new light. Both infrastructure and vehicular technologies can be tested in this environment to gain a more complete picture of the safety effects of a proposed project. While it will take greater modeling fidelity and statistical driver models to fully realize the potential of this research, the collaboration between civil and mechanical engineers has begun to realize the interactions between our spheres in real life and the value of connecting those spheres in research. 


\section{REFERENCES}

AAAM. (2014). About AIS. Retrieved 3 21, 2014, from http://www.aaam.org/about-ais.html

Adam, T. (2011). Identification of Occupant Posture using a Pattern Recognition Methodology to Reduce the Risk of Injury in a Collision. Master's Thesis, University of Virginia, Mechanical and Aerospace Engineering.

Amundson, F., \& Hyden, C. (1977). Proceedings of first workshop on traffic conflicts. Institute of Economics.

Arbelaez, R., Baker, B., \& Nolan, J. (2005). Delta Vs for IIHS side impact crash tests and their relationship to real-world crash severity. United States: Insurance Institute for Highway Safety.

Autey, J., Sayed, T., \& Zaki, M. (2012). Safety evaluation of right-turn smart channels using automated traffic conflict analysis. Accident Analysis and Prevention, 45, 120-130.

Boström, O. e. (1996). A new neck injury criterion candidate based on injury findings in the cervical spine ganglia after experimental neck extension trauma. International IRCOBI conference on the Biomechanics of Impacts. Dublin, Ireland.

Chin, H., \& Quek, S. (1997). Measurement of traffic conflicts. Safety Science, 26(3), 169-185.

Davis, G., Hourdos, J., Xiong, H., \& Chatterjee, I. (2011, May). Outline for a causal model of traffic conflicts and crashes. Accident Analysis and Prevention, 43, 1907-1919.

El-Basyouny, K., \& Sayed, T. (2013). Safety performance functions using traffic conflicts. Safety Science, 51, 160-164.

Eppinger, R. e. (1999). Development of Imrpoved Injury Criteria for the Assessment of Advanced Automotive Restraint Systems - II. National Highway Traffic Safety Administration (NHTSA).

Funk, J. e. (2002, December). The effect of active muscle tension on the axial injury tolerance of the human foot/ankle complex. Journal of Biomedical Engineering, 124(6), 750-757.

Gennarelli, T., \& Wodzin, E. (2008). The Abbreviated Injury Scale 2005. Update 2008. Des Plaines, IL: American Association for Automotive Medicine (AAAM).

Gettman, D. e. (2008). Surrogate Safety Assessment Model and Validation: Final Report. FHWA. 
Huang, F. e. (2013). Identifying if VISSIM simulation model and SSAM provide reasonable estimates for field measured traffic onflicts at signalized intersections. Accident Analysis and Prevention, 50, 1014-1024.

Humanetics ATD. (2014). BioRID-II. Retrieved 3 14, 2014, from http://www.humaneticsatd.com/crashtest-dummies/rear-impact/biorid-ii

Humanetics ATD. (2014). Hybrid III 50th Male Dummy. Retrieved 3 14, 2014, from http://www.humaneticsatd.com/crash-test-dummies/frontal-impact/hybrid-iii-50th

Kullgren, A., Eriksson, L., Bostrom, O., \& Krafft, M. (2005). Validation of neck injury criteria using reconstructed real-life rear-end crashes with recorded crash pulses. 18th ESV Conference Proceedings. NHTSA Enhanced Safety Vehicles (ESV).

Kuppa, S., Wang, J., Haffner, M., \& Eppinger, R. (2001). Lower Extremity Injuries and Associated Injury Criteria. Proc. 17th ESV Conf., 1-15.

Kusano, K., \& Gabler, H. (2012, December). Safety benefits of forward collision warning, brake assist, and autonomous braking systems in rear-end collisions. IEEE Transactions on Intelligent Transportation Systems, 13(4), 1546-1555.

NHTSA. (1997). Actions to Reduce the Adverse Effects of Air Bags. Washington DC: National Highway Traffic Safety Administration.

Park, B., \& Lee, J. (2009). Optimization of coordinated-actuated traffic signal system. Transportation Research Record: Journal of the Transportation Research Board, 2128, 76-85.

Park, B., Chen, Y., \& Hourdos, J. (2011). Opportunities for preventing rear-end crashes: Findings from the analysis of actual freeway crash data. Journal of Transportation Safety \& Security, 3(2), 95107.

Pu, L., \& Joshi, R. (2008). Surrogate Safety Assessment Model (SSAM): Software User Manual. Federal Highway Administration.

Rumar, K. (1985). The role of perceptual and cognitive filters in observed behavior. In L. Evans, \& R. Schwing (Eds.), Human Behavior and Traffic Safety. London: Plenum Press. 
Saunier, N., \& Sayed, T. (2006). A feature-based tracking algorithm for vehicles in intersections. Computer and Robot Vision, the 3rd Canadian Conference, 59.

Saunier, N., \& Sayed, T. (2007). Automated road safety analysis using video data. Transportation Research Record: Journal of the Transportation Research Board, 2019, 57-64.

So, J., Park, B., Wolfe, S., \& Dedes, G. (n.d.). Development and Validation of a Vehicle DynamicsIntegrated Traffic Safety Simulation Enviornment for Enhanced Surrogate Safety Measures. Journal of Computing in Civil Engineering, in press.

Sobhani, A., Young, W., \& Sarvi, M. (2013). A simulation based approach to assess the safety performance of road locations. Transportation Research Part C, 144-158.

Svensson, Å., \& Hyden, C. (2005). Estimating the severity of safety related behavior. Accident Analysis and Prevention, 38, 379-385.

Tarko, A. (2012). Use of crash surrogates and exceedance statistics to estimate road safety. Accident Analysis and Prevention, 45, 230-240.

TASS. (2013). MADYMO Applications Manual, Version 7.5. TASS International. Retrieved from www.tassinternational.com

Vision Zero Initiative. (2013). The Vision Zero Initiative. Retrieved 3 14, 2014, from http://www.visionzeroinitiative.com/en/Concept/

Young, W., Sobhani, A., \& Sarvi, M. (2014). An exploratory review of the literature on computer simulation models of safety on roads. TRB Annual Meeting Compendium of Papers. Washington, DC: Transportation Research Board. 


\section{APPENDIX A: $\quad$ Logistic vs. Weibull Distributions}

\begin{tabular}{|l|c|c|}
\hline & Logistic Function & Weibull Function \\
\hline CDF & $P(x)=\frac{1}{1+e^{a+b x}}$ & $P(x)=1-e^{-(x / \lambda)^{k}}$ \\
\hline Slope of CDF (or PDF) & $f(x)=-\frac{b e^{a+b x}}{\left(e^{a+b x}+1\right)^{2}}$ & $f(x)=\frac{k}{\lambda}\left(\frac{x}{\lambda}\right)^{k-1} e^{-(x / \lambda)^{k}}$ \\
\hline X by percentile & $x(P)=\frac{1}{b}\left[\ln \left(\frac{1-P}{P}\right)-a\right]$ & $x(P)=\lambda\left[\ln \left(\frac{1}{1-P}\right)\right]^{1 / k}$ \\
\hline Slope by percentile & $f(P)=b(P-1) P$ & $f(P)=\frac{k}{\lambda}(1-P)\left[\ln \left(\frac{1}{1-P}\right)\right]^{k-1 / k}$ \\
\hline X at $\mathrm{P}=0.5$ & $x(0.5)=-a / b$ & $x(0.5)=\lambda[\ln (2)]^{1 / k}$ \\
\hline Slope at $\mathrm{P}=0.5$ & $f(0.5)=b / 4$ & $f(0.5)=\frac{k}{2 \lambda}[\ln (2)]^{k-1 / k}$ \\
\hline $\begin{array}{l}\text { Equal } \mathrm{X} \text { at } \mathrm{P}=0.5 \\
\text { Equal slope at } \mathrm{P}=0.5\end{array}$ & \multicolumn{2}{|c|}{$\lambda=-\frac{a}{b}[\ln (2)]^{2 \ln (2) / a}$} \\
\hline
\end{tabular}

Comparison for $\mathrm{N}_{\mathrm{ij}}$ logistic risk curves from (Eppinger, et al., 1999)

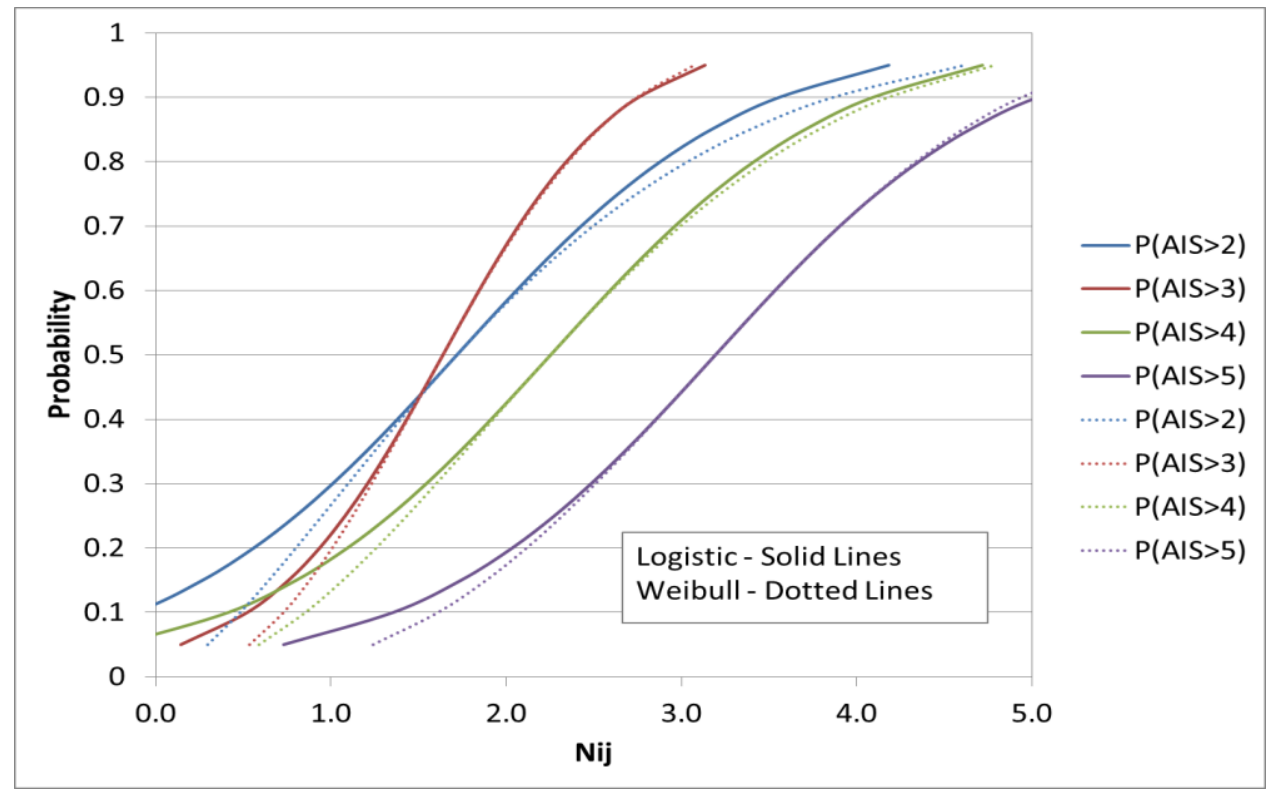




\section{APPENDIX B: $\quad$ Injury Function Development}

The forces obtained from MADYMO are summarized below. The relative speed of $46 \mathrm{kph}$ was run with and without the airbag to connect the two parts of the model

\begin{tabular}{|c|c|c|c|c|c|c|}
\hline \multirow{4}{*}{$\begin{array}{c}\text { Relative } \\
\text { speed } \\
\mathrm{km} / \mathrm{h}\end{array}$} & \multicolumn{6}{|c|}{ Injury Output } \\
\hline & trontar & \multicolumn{5}{|c|}{ Following car } \\
\hline & Neck & Head & Neck & Thorax & Upper leg & Lower leg \\
\hline & $\mathrm{NIC}_{\max }$ & HIC & $\mathrm{N}_{\mathrm{ij}}$ & $\mathrm{C}_{\mathrm{disp}}(\mathrm{m})$ & FFC (KN) & TCFC (KN) \\
\hline 10 & 4.64 & 0.75117 & 0.0559 & 0.0094 & 0.412 & 0.44 \\
\hline 20 & 21.99 & 1.218 & 0.0904 & 0.00952 & 0.425 & 0.795 \\
\hline 25 & 25.25 & 2.568 & 0.113 & 0.01314 & 0.43 & 0.914 \\
\hline 30 & 31.66 & 4.4897 & 0.1396 & 0.0171 & 0.508 & 1.254 \\
\hline 35 & 36.14 & 6.581 & 0.1577 & 0.0207 & 0.611 & 1.705 \\
\hline 40 & 39.99 & 9.3642 & 0.1788 & 0.0236 & 0.701 & 2.107 \\
\hline 45 & 50.47 & 12.73 & 0.1932 & 0.0244 & 0.842 & 2.474 \\
\hline 46 & & 13.59 & 0.1952 & 0.0245 & 0.871 & 2.583 \\
\hline 46 (airbag) & & 16.25 & 0.1753 & 0.0275 & 0.862 & 2.583 \\
\hline 50 (airbag) & 64.67 & 21.44 & 0.1742 & 0.0285 & 0.922 & 2.814 \\
\hline 60 (airbag) & 72.36 & 37.98 & 0.1724 & 0.0298 & 1.009 & 3.764 \\
\hline
\end{tabular}

B-2 


\begin{tabular}{|c|c|c|c|c|c|c|c|}
\hline \multirow{2}{*}{$\begin{array}{c}\text { Relative } \\
\text { speed } \\
\mathrm{km} / \mathrm{h}\end{array}$} & \multicolumn{7}{|c|}{ Injury Risk } \\
\hline & Frontal car & \multicolumn{6}{|c|}{ Following car } \\
\hline & Neck & Head & Neck & Thorax & Upper leg & Lower leg & $\mathrm{WIC}^{\prime}$ \\
\hline & AIS 1 & AIS 2 & AIS 2 & AIS 2 & AIS 2 & AIS 2 & \\
\hline 10 & $0.00 \%$ & $0.0000 \%$ & $0.4320 \%$ & $0.0008 \%$ & $0.3773 \%$ & $1.3691 \%$ & 0.003225 \\
\hline 20 & $31.00 \%$ & $0.0000 \%$ & $0.8786 \%$ & $0.0008 \%$ & $0.3798 \%$ & $1.7304 \%$ & 0.004385 \\
\hline 25 & $63.00 \%$ & $0.0000 \%$ & $1.2207 \%$ & $0.0013 \%$ & $0.3808 \%$ & $1.8713 \%$ & 0.005069 \\
\hline 30 & $99.00 \%$ & $0.0000 \%$ & $1.6660 \%$ & $0.0018 \%$ & $0.3965 \%$ & $2.3389 \%$ & 0.006409 \\
\hline 35 & $100.00 \%$ & $0.0000 \%$ & $1.9925 \%$ & $0.0024 \%$ & $0.4182 \%$ & $3.1382 \%$ & 0.008094 \\
\hline 40 & $100.00 \%$ & $0.0000 \%$ & $2.3950 \%$ & $0.0028 \%$ & $0.4381 \%$ & $4.0687 \%$ & 0.010079 \\
\hline 45 & $100.00 \%$ & $0.0000 \%$ & $2.6824 \%$ & $0.0030 \%$ & $0.4712 \%$ & $5.1445 \%$ & 0.012144 \\
\hline 46 & $100.00 \%$ & $0.0000 \%$ & $2.7230 \%$ & $0.0030 \%$ & $0.4783 \%$ & $5.5128 \%$ & 0.012765 \\
\hline 46 & $100.00 \%$ & $0.0000 \%$ & $2.3267 \%$ & $0.0035 \%$ & $0.4761 \%$ & $5.5128 \%$ & 0.012219 \\
\hline 50 & $100.00 \%$ & $0.0008 \%$ & $2.3054 \%$ & $0.0037 \%$ & $0.4910 \%$ & $6.3768 \%$ & 0.013517 \\
\hline 60 & $100.00 \%$ & $0.0514 \%$ & $2.2706 \%$ & $0.0039 \%$ & $0.5136 \%$ & $11.4040 \%$ & 0.021275 \\
\hline
\end{tabular}

Related graphs and fit lines:

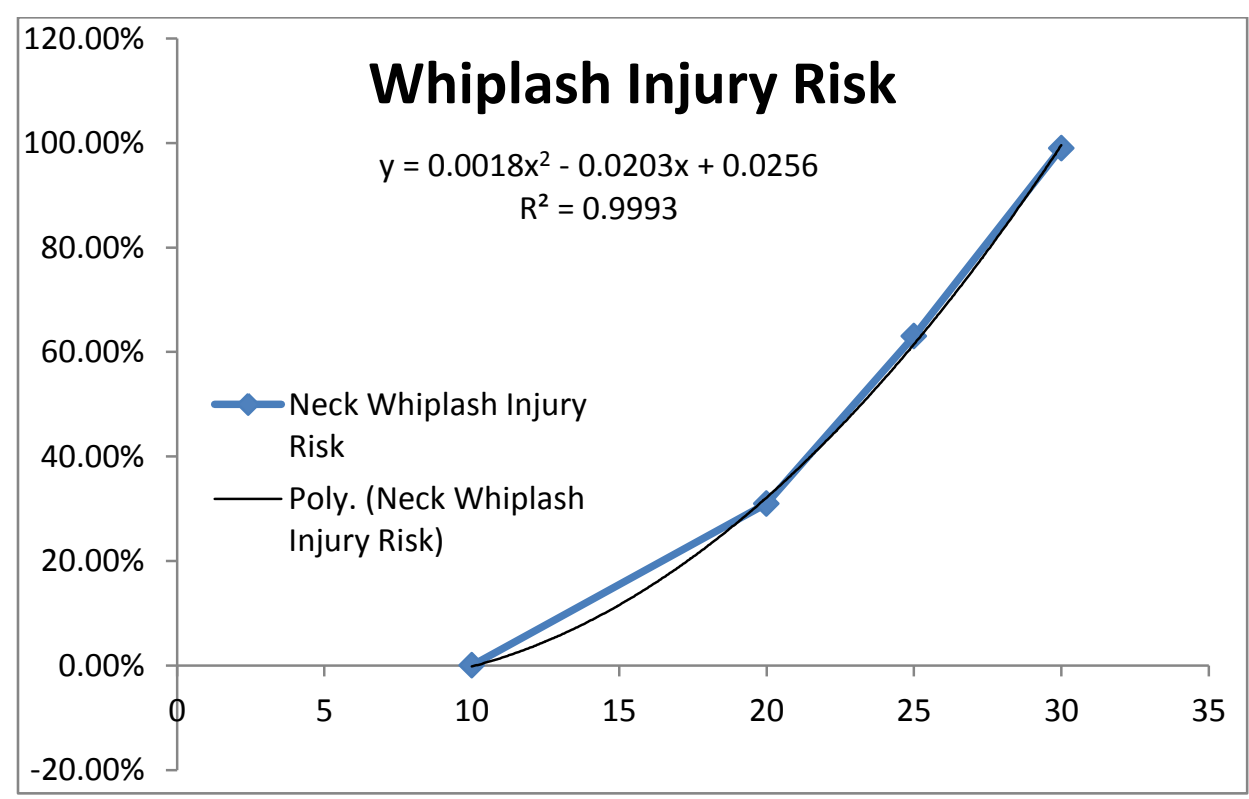

B-3 

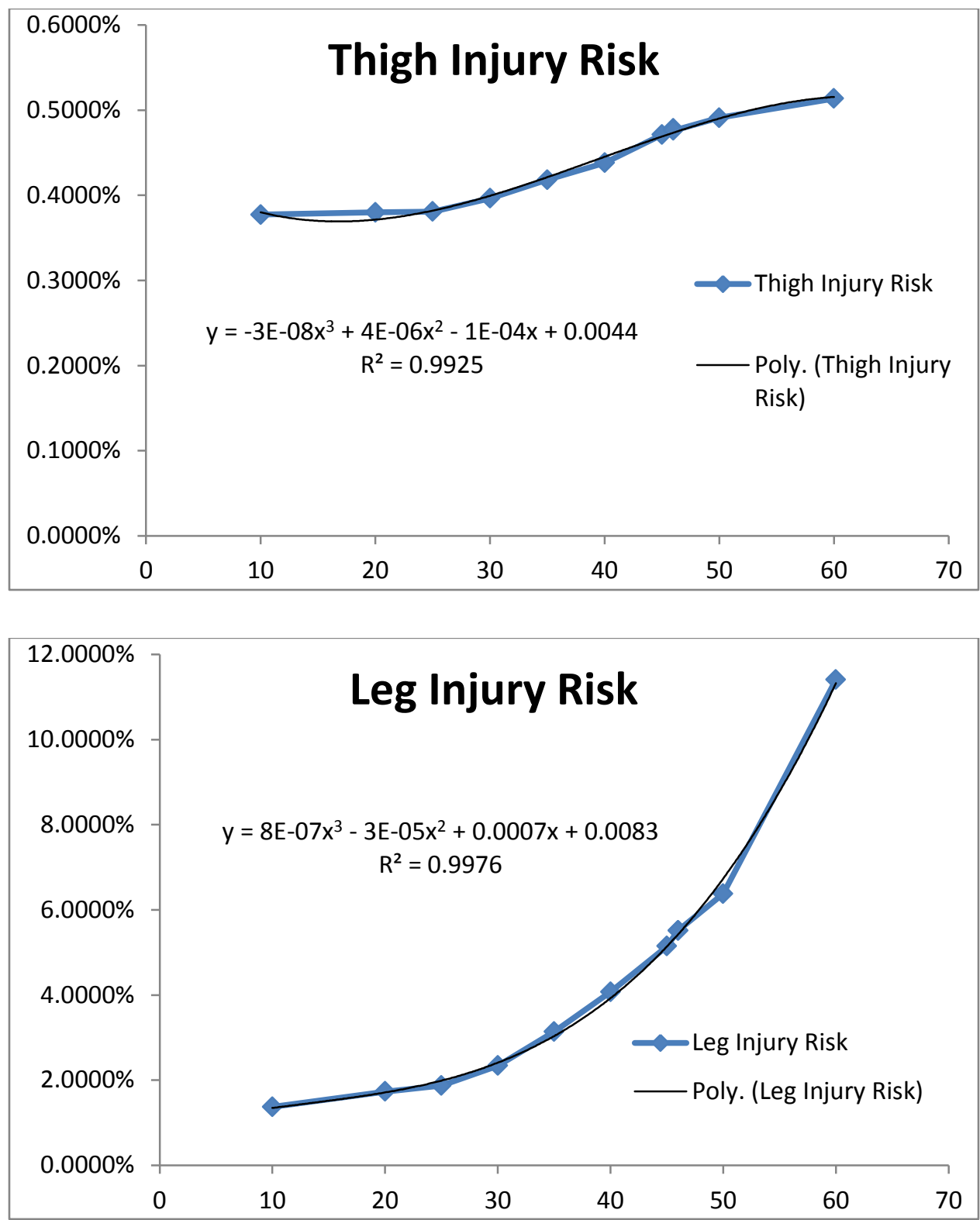

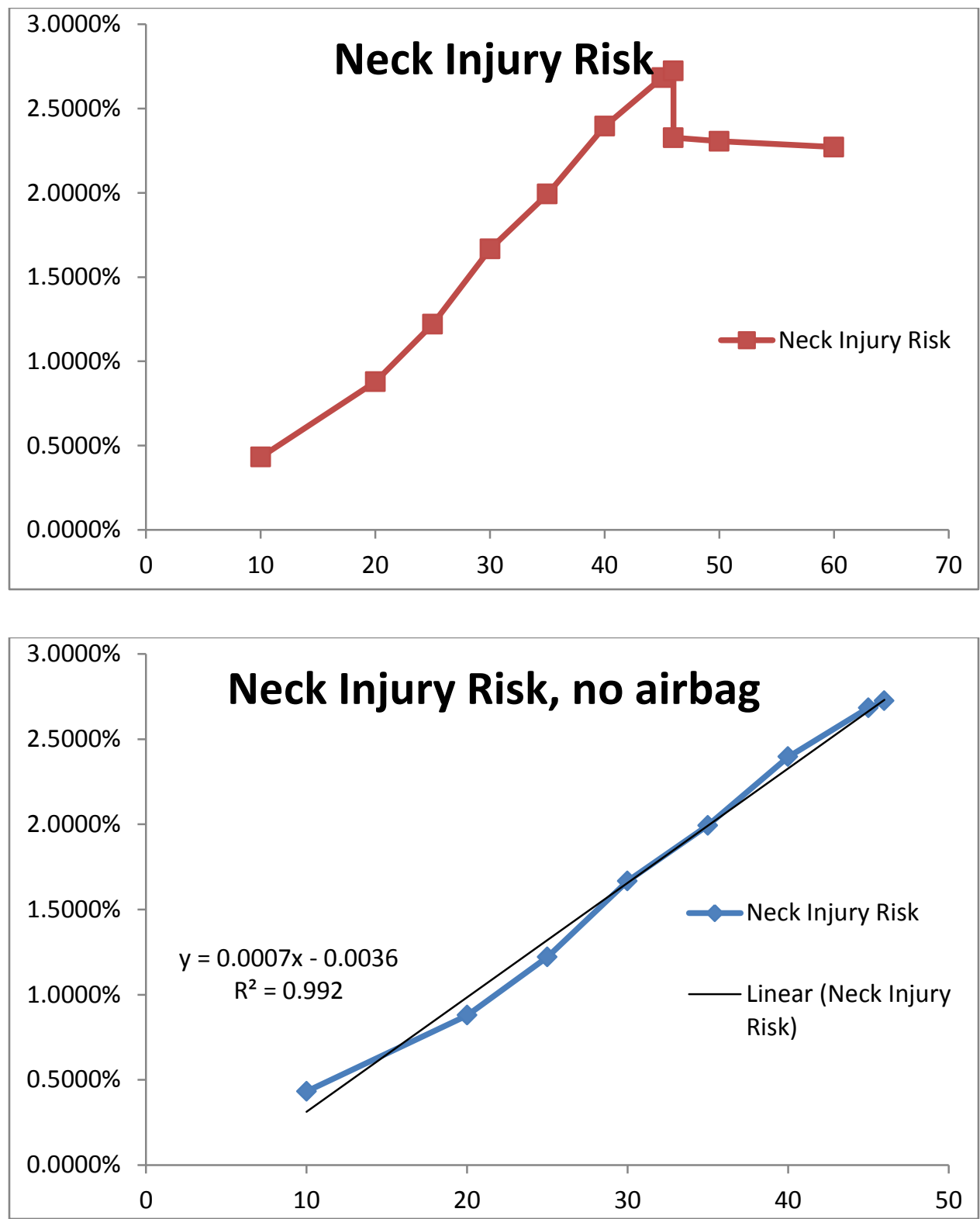


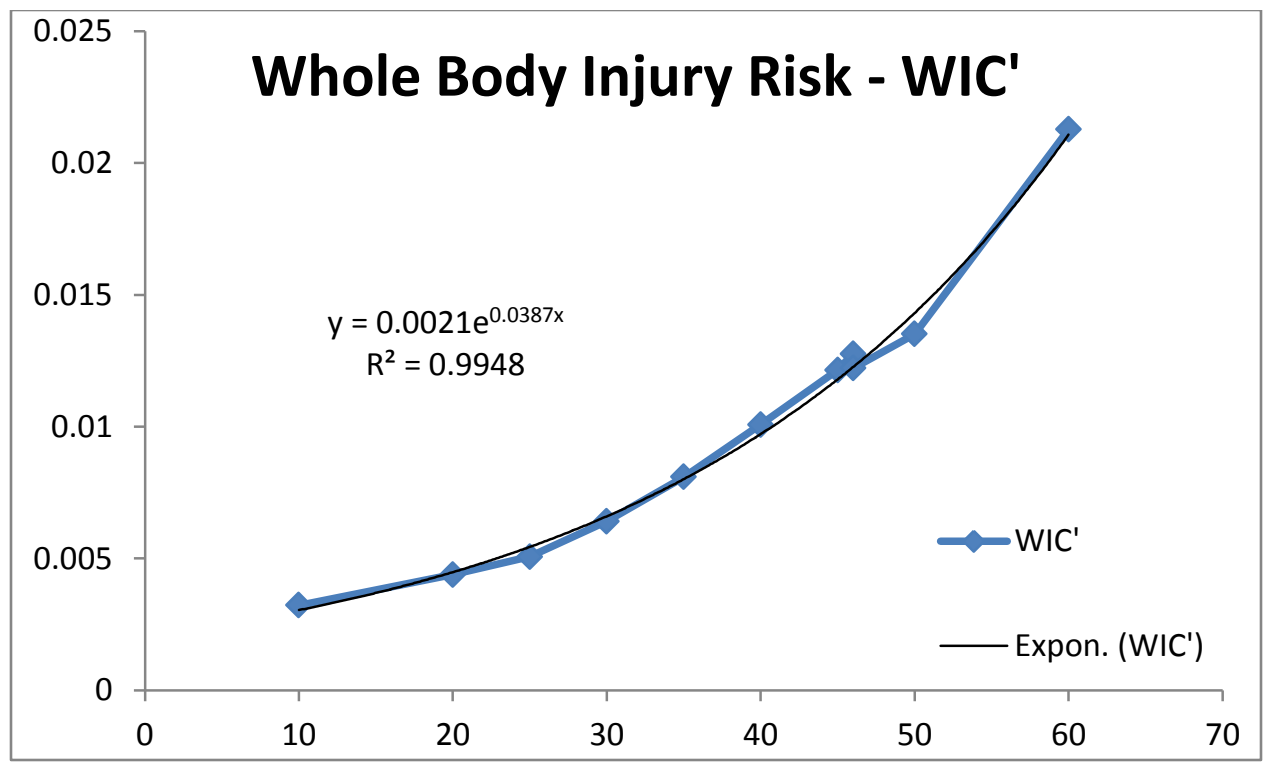

B-6 